\title{
Survivorship in Women Undergoing Gynecological and Breast Cancer Treatment in Upper Egypt: The Impact of Quality of Life Improvement Educational Program
}

Fatma Saber Nady Mohammed ${ }^{1}$, Mamdouh El-Sherbiny Ramadan Shahin ${ }^{2}$, Entisar Mohammed Youness ${ }^{3}$, Hanan Elzeblawy Hassan ${ }^{* 4}$

${ }^{1}$ Assistant lecturer in Maternal \& Newborn Health Nursing, Faculty of Nursing, Beni-Suef University, Egypt

${ }^{2}$ Professor of Oncology, Faculty of Medicine, Beni-Suef University, Egypt

${ }^{3}$ Assistant Professor of Obstetrics and Gynecological Nursing, Faculty of Nursing, Assuit University, Egypt

${ }^{* 4}$ Maternal and Newborn Health Nursing, Faculty of Nursing, Beni-Suef University, Egypt

*nona_nano_1712@yahoo.com

Abstract

Background: Quality of life data, in cancer care, have played a crucial role in the selection of therapeutic agents that have become the standard of care. However, the dramatic increase in the number of survivors living, five years post-diagnosis of breast and gynecological cancer, benefits related to quality of life have not been achieved. Quality of life issue is of interest in oncology because effective modern methods of treatment and detection have led to an increase in the number of long-term survivors.

Aim: assess the effectiveness of an educational program on quality of life improvement in women undergoing treatment for gynecological and breast cancer.

Study design: A quasi-experimental study design.

Sample and settings: A randomly selected sample of 100 women diagnosed with gynecologic and breast cancer that attended El-Minia Oncology Institute.

Tool: A structured interview questionnaire included Female Sexual Function Index, Cancer-Specific Stress, and The Functional Assessment of Cancer Therapy-General.

Results: Quality of life of the studied women with breast and gynecological cancer have been improved under the influence of educational program and this improvement has not been only related to the total score of the quality of life but also has occurred in physical, social, emotional, and functional well-being subscales.

Conclusion: The educational program showed evidence of improved quality of life, with a reduction in the sexual dysfunction, and lower stress levels.

Recommendations: Based on findings of the current study, it is suggested to heighten awareness and knowledge about the breast and gynecologic cancer treatment-related side effects among the nursing staff.

Keywords: Survivorship, Gynecological Cancer, Breast Cancer, Sexual Dysfunction, Quality of Life. INTRODUCTION

Cancer is that the most significant worldwide pathologic health problem with wide geographical variation in incidence and it has additionally become an important item in each country's health agenda. ${ }^{[1]}$ In Egypt, the commonest cancer sites in females are breast (38.8\%), and ovary (4.5\%). ${ }^{[2]}$ The prevalence of breast carcinoma is high and the cases of breast cancer constitute $29 \%$ of cancer cases treated at the national cancer institute. ${ }^{[3,4]}$

www.arjonline.org

Page 1 
Survivorship in Women Undergoing Gynecological and Breast Cancer Treatment in Upper Egypt: The Impact of Quality of Life Improvement Educational Program

Since the start of the 80s of the most recent century, the interest in the field of Quality of Life (QOL) has grown significantly with numerous studies that were directed in this research area. ${ }^{[5,6]}$ While a wide body of literature already dealt with QOL, the meaning of this term is as yet indistinct and raises a debate among practitioners, professionals \& researchers that are engaged in this field. While there is a debate among researchers for the meaning of QOL, this term has an inherent meaning to most people. ${ }^{[7]}$ World Health Organization (WHO) defines QOLas a person's impression of their position in life in the context of the culture \& value systems in which they live in relation to their goals, expectations, standards \& concerns. It is a broad-ranging concept affected in a complex way by the persons' physical wellbeing, mental state, \& level of autonomy, social relationships, and their relationship to salient features of their environment ${ }^{\left[{ }^{[8]}\right.}$ Briefly, QOL is a broad multidimensional concept that comprises of several aspects; person's physical, mental and psychological, emotional, social, and spiritualwell-being. ${ }^{[9,10]}$ Physical well-being is the degree to which symptoms and side effects, such as pain, fatigue, and poor sleep quality, affect the ability to perform normal daily activities. Emotional, or psychological, well-being refers to the ability to maintain control over anxiety, depression, fear of cancer recurrence, and problems with memory and concentration. Social well-being primarily addresses relationships with family members and friends, including intimacy and sexuality. Employment, insurance, and financial concerns also affect social well-being. Finally, spiritual well-being is derived from drawing meaning from the cancer experience, either in the context of religion or through maintaining hope and resilience in the face of uncertainty about one's future health. ${ }^{[9]}$

Today, women diagnosed with early cancer are thought to have close to a $90 \%$ chance of survival. Over 84,000 women are diagnosed with gynecological cancer each year. ${ }^{[11]}$ There are five main types of cancer that affect a woman's reproductive organs: cervical, ovarian, uterine, vaginal, and vulvar. As a group, they are referred to as gynecologic cancer. The sixth type of gynecologic cancer is (the very rare) Fallopian tube cancer. ${ }^{[12,13]}$ Due to the dramatic increase in the number of survivors living five years post-diagnosis of breast and gynecologic cancer, there has been greater recognition given to the ongoing and emergent sequelae of cancer and its impact on health related quality of life (HRQOL). ${ }^{[14]}$ Health-related QOL is a quality of life term that takes into account the impact an illness has on an individual's QOL. Although HRQOL is suggested in the literature to be a subjective patient-reported outcome (PRO), many of the current instruments used to measure HRQOL for cancer survivors continue to adopt a biomedical clinical-centered approach. ${ }^{[15]}$

Quality of life data, in cancer care, has played a crucial role in the selection of therapeutic agents that have become the standard of care. In addition, information about QOL is also important for planning treatment, decision making, providing supportive care, determine whether a new therapy is preferable to standard therapy, compare two standard therapies having similar survival outcomes, identify the long-term negative effects of therapy, when survival time is long, discover whether a therapeutic regimen is better than supportive care only, when survival time is short, determine the negative effects of adjuvant therapy, identify the need for supportive care, and target problems and facilitate communication in clinical practice. Such information is useful for both clinicians and patients, as well as to promote communication among them. Oncology nurses play a critical role in providing QOL information to patients so that they can make better-informed decisions about their treatment. ${ }^{[16]}$

For many patients with cancer, the goal of therapy is as much improved QOL as it is eliminating the tumor cells. While QOL varies markedly among cancer types, a considerable proportion of all patients experience negative effects of cancer and its treatments resulting in decreased QOL. Individuals who have a history of more invasive and aggressive treatments tend to report poorer functioning and QOL in the long term. ${ }^{[17]}$ According to data from the National Health Interview Survey, approximately 1 in 4 cancer survivor reports a decreased quality of life (QOL) due to physical problems and 1 in 10 due to emotional problems..$^{[9]}$ So, assessing and improving QOL status in cancer women is important for several reasons, particularly because it provides supplementary information about the impact of the disease and its treatment on cancer women to aid health care providers in

American Research Journal of Gynaecology

Page 2 
Survivorship in Women Undergoing Gynecological and Breast Cancer Treatment in Upper Egypt: The Impact of Quality of Life Improvement Educational Program

selecting both antineoplastic \& supportive-care therapy. Given the chronic and often incurable nature of many gynecologic malignancies, the toxicity and tolerability of a specific therapy that might be as important as its efficacy, as is the ability to help ameliorate or prevent many of the associated toxicities that negatively affect QOL.

\section{Significance of the Study}

An estimated 426 women in Egypt diagnosed with uterine endometrial cancer, 752 cases diagnosed with cervical cancer, 103 cases diagnosed with vaginal cancer, 56 cases diagnosed with vulvar carcinoma and 2434 cases diagnosed with ovarian cancer in 2014. Moreover, 19105 female cases diagnosed with breast cancer in the same year. ${ }^{[2]} \mathrm{An}$ increase in the number and distress of symptoms is associated with decreased QOL. ${ }^{[18]}$ Women have indicated that unmanaged symptoms have a negative impact on all the dimensions of QOL including their physical, social, psychological, and spiritual well-being. ${ }^{[19]}$

With respect to the dimensions of QOL, all studies demonstrate that pain and fatigue influence all four dimensions, and thus reduce the QOL in cancer patients. Many authors specified the determinant factors that may lead to adecrease in QOL in cancer patients and divided them into three categories: those related to general health (physical, social and psychological), those directly related to the disease, and those related to treatment. ${ }^{[20,21]}$

Nurses having a vital role in the health care system as well as play an important role in this area as educators as well as health promoters of patients. Additionally, they should also collaborate with other different health professionals to determine the effectiveness of therapy. ${ }^{[1]}$ The Skill Acquisition Nursing Evidence-Based Practice domains that delivered best outcomes for the breast and gynecological cancer survivors include; the helping role, the teaching coaching function, patient assessment (diagnostic \& patient monitoring function), coordination of care, administering \& monitoring therapeutic interventions and regimens, monitoring \& ensuring the quality of healthcare practices, organizational and work role competencies, supportive care..$^{[22-24]}$

Health care provider, especially nurse, their involvementin cancer survivorship care is essential for promoting and overseeing healthy lifestyle adaptations necessary to decrease the susceptibility risk of cancer recurrence and post-cancer treatment complications, as well as secondary illness unrelated to cancerdiagnosis. ${ }^{[25]}$ The Institute of medicine reported recognized four essential components of patient-centered survivorship care: prevention of recurrent and new cancers and other late effects, surveillance for cancer spread, recurrence, or second cancers and assessment of medical and psychosocial late effects, interventions for consequences of cancer and its treatment, and coordination between specialists and primary care providers (PCPs) to ensure that all of the survivor's health needs are met. ${ }^{[26]}$

Maternity nurse, as one of health care providers, it is essential to educate women about risks, screening, prevention, and new therapies available for treatment to continue to advance survivorship and continue the favorable trends that are being realized in breast cancer care. ${ }^{[27]}$ The usual care given by the nurse during cancer treatment tends to focus on procedures, side effects of treatment, and its process rather than on the resulting symptoms and their management. Therefore, a more comprehensive approach to helping this group of women with their symptom management is suggested to be conducted through this study.

\section{Aim of the Study}

The present study was conducted to assess the effectiveness of education program on QOL improvement in women undergoing treatment for gynecological and breast cancer.

\section{Research Hypothesis}

Quality of life of women with gynecological and breast cancer who receives educational program will be improved than those who won't. 
Survivorship in Women Undergoing Gynecological and Breast Cancer Treatment in Upper Egypt: The Impact of Quality of Life Improvement Educational Program

\section{Methods And Subjects}

\section{Research design}

A quasi-experimental research design was adopted.

\section{Setting}

The study was conducted in the oncology institute which was the only health-care setting providing health-care services to gynecology oncology women in El-Minia region.

\section{Study subjects}

A randomly selected sample of women diagnosed with gynecologic and breast cancer that attended the oncology institute and recruited randomly. Total attendance per week ranged from 1-2 cases for gynecologic cancer and 2-3 cases for breast cancer. The total number of women included in the study was 90 women. The sample size was raised to 100 women for greater power of the study and to safeguard against any missing items of the questionnaire and get more informative results. The sample calculated by the formula for quasi-experimental study. ${ }^{[28]}$

$$
\mathrm{n}=\frac{\left(\mathrm{Z}_{1-\alpha / 2}+\mathrm{Z}_{1-\beta}\right)^{2} * p^{*} q}{\left(\mathrm{p}_{1}-\mathrm{p}_{0}\right)^{2}}
$$

Where, $n=$ minimum sample size for each group; $Z_{1-\alpha / 2}=$ value of alpha error; $Z_{1-\beta}=$ value of beta error; for the usual situation when alpha error $=0.05$ two-tailed, the value is 1.96 and for beta error $=0.20$, it is $0.84 ; \mathrm{P}_{0}=$ Proportion of those without the outcome who are likely to have the exposure.

The sample divided into 2 main groups; Sixty-four women (32 "study" \& 32 "control") for the breast cancer group and thirty-six women (18 "study" \& 18 "control") for the gynecologic group. Each group from study and control assigned to the line of management according to the randomization method. Randomization was done using a computer-generated random table. After acceptance of eligible women to participate in the study, they were assigned randomly to either one of the above groups. Allocation concealment was done using a serially-numbered closed opaque envelope. Counseling for participation was done before recruitment. Once allocation for participation has been done, it could not be changed. Study group in both main groups followed the recommended QOL improvement educational program at the oncology institute, while control group in both main groups followed the routine care at the oncology outpatient clinic.

\section{Inclusion Criteria}

1. Women who had been diagnosed with gynecological cancer such as uterine, ovarian, cervical, vulval or vaginal cancers and breast cancer over the past 3 months.

2. Married women aged 20-55 years who have sexual intercourse at least in the last month.

3. Premenopausal or postmenopausal (defined by amenorrhea of $\geq 6$ months).

4. Ability to give informed consent.

\section{Exclusion Criteria}

1. Additional cancer diagnoses (including metastasis).

2. Inability to provide informed consent.

3. Married women who did not have sexual intercourse in the last month, were pregnant or delivered in the last 6 months or widowed. 
Survivorship in Women Undergoing Gynecological and Breast Cancer Treatment in Upper Egypt: The Impact of Quality of Life Improvement Educational Program

\section{Tools of the Study}

Four tools filled by the researchers after an extensive review of recent relevant literature about gynecologic and breast cancer. It consisted of:

\section{Tool (I): A Structured Interview Questionnaire}

It was included socio-demographic data, obstetrical \& gynecological history, sources of social stressors, clinical characteristics including information about disease site (breast vs. gynecologic), previous consultation for gynecological complaints, stage at diagnosis, and type of treatment as well as oncology treatment side effects record, which included a question about side effect post-chemotherapy treatment.

\section{Tool (II): Female Sexual Function Index (FSFI) ${ }^{[29]}$}

The FSFI which is a 19-item self-report measure. It was translated into Arabic by the researchers to assess sexual functioning during the past 4 weeks. Principal components analysis yields six subscales: desire, arousal, lubrication, orgasm, satisfaction, and pain. Items are rated using a six-point Likert scales (e.g.; Over the past four weeks, how often did you feel sexual desire or interest? $5=$ almost always or always, $4=$ most times (more than half the time), 3 = Sometimes (about half the time), $2=$ A few times (less than half the time), $1=$ Almost never or never

\section{Scoring System}

Subscale scores are calculated by adding the Likert responses and multiplying the sum bya domain factor (as specified in scoring instructions. ${ }^{[29]}$ The total score was calculated by summing the six domain scores. ${ }^{[30]}$

1. The lowest score was calculated as 2 and the highest score as 36.

2. The total FSFI score under 26.55 was accepted as female sexual dysfunction (FSD).

\section{Tool (III): Cancer-Specific Stress (CSS)}

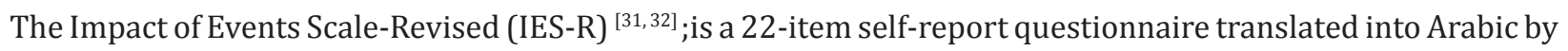
the researchers to assess traumatic stress reactions to cancer diagnosis and treatment. Factor analytic studies indicate that the measure assesses three factors (corresponding tothe post-traumatic stress disorder "PTSD" clusters): intrusive thoughts, avoidant thoughts/behaviors, and hyper-arousal. Women rated thefrequency of these feelings or events during the previous week, using a five-point Likertscale ranging from $0=$ not at allto 4 $=$ extremely. Items were summed for a total score thatranges from 0 to 88, with higher scores reflecting greater cancer-related stress. Authors recommend a cut-off score of 33 for identifying patients with clinical symptoms of post-traumatic stress.

Scoring System

On this test, scores that exceed 24 can be quite meaningful. High scores have the following associations:

1. 24 or milder "PTSD": PTSD is a clinical concern. Those with scores that are high who do not have full PTSD will have partial PTSD or at least some of the symptoms.

2. 33 and above moderate "PTSD": This represents the best cutoff for a probable diagnosis of PTSD.

3. 37 or more "severe PTSD": This is high enough to suppress women immune system's functioning (even 10 years after an impact event).

Tool (IV): The Functional Assessment of Cancer Therapy-General (TCHI FACT-G) to measure the QOL The Traditional Chinese version of the Functional Assessment of Cancer Therapy-General (TCHI FACT-G), 
Survivorship in Women Undergoing Gynecological and Breast Cancer Treatment in Upper Egypt: The Impact of Quality of Life Improvement Educational Program

Version 4 translated into Arabic to be used in measurement of the impact of gynecologic and breast cancer and related treatment on patients' QOL. It is considered appropriate for use with patients with any form of cancer. ${ }^{[33]}$

The TCHI FACT-G version 4 includes 36 items and covers four primary QOL domains: physical well-being (PWB; 7 items), emotional well-being (EWB; 6 items), social well-being (SWB; 7 items) and functional well-being (FWB; 7 items), additional concerns ( 9 items). A five-point Likertscale was used ( $0=$ not at all, $1=$ a little bit, 2 = somewhat, 3 = quite a bit, 4 = verymuch), which provided four subscale scores and a total score ranging from 0 to 144 , a higher score meaning a poor QOL, a lower score indicating high QOL and low effect of gynecologic and breast cancer treatment on QOL.

\section{Scoring System}

1. $0-33 \%$

Mild affection "good QOL"

2. $33.3-66.7 \%$

Moderate affection "average QOL"

3. $>66.7 \%$

Severe affection "poor QOL".

\section{Methods and Phases of Data Collection}

\section{Validity \& Reliability of Tool}

All used scales were standardized that did not require any test for validity \&reliability except the Functional Assessment of Cancer Therapy-General to assess QOL so, the researcher distributed the questionnaire to a panel of five specialists in obstetrics \& gynecologic nursing, oncology nursing staff, and medical related specialists in Beni-Suef and Assiut University to check the validity of the tool used. Reliability of tool was tested by using Cronbach's Alpha coefficient test, which revealed high reliability $=0.85$.

\section{Administrative Approval}

A written permission clarifying the purpose of the study was obtained from the dean of the faculty of nursing in Beni-Suef and Assiut university to the ministry of health and then to the medical and nursing directors of the oncology institute in EL-Minia government.

\section{Ethical Approval}

A written or oral consent accordingly to conduct the study was taken from each studied women to protect their rights before the start of the study. They were informed that they could withdraw at any time. A unique identifying number (subject ID) was assigned to the data collected from each woman to maintain confidentiality.

\section{Pilot Study}

A pilot study carried out on $10 \%$ of the women which was equal to (10 women). The aim of this pilot study was to test the clarity, comprehensiveness, and applicability of the tools and to estimate the appropriate time required to fill the questionnaire. Based on the result of the pilot study, no major modifications in the tools were done; the cases of the pilot study weren't excluded.

\section{Phases of Field Work}

\section{(A): The Preparatory Phase}

It included reviewing of related literature and theoretical knowledge of various aspects of the study using books, articles, internet, periodicals, and magazines, also, getting official permission, preparation of the tool, preparation of the booklet. 
Survivorship in Women Undergoing Gynecological and Breast Cancer Treatment in Upper Egypt: The Impact of Quality of Life Improvement Educational Program

(B): Implementation Phase

Once the permission was granted to proceed with the proposed study, the researcher initiated data collection by reviewing the visits appointment in the selected settings of the study. The researcher interviewed the women face to face in the day of visit in the Oncology Institute at El-Minia government in the outpatient clinic, waiting room 2 days per week from 9 a.m. to 2 p.m. during the period from January 2016 to June 2017. The researcher contacted participant who met the criteria for inclusion. The interviewing questionnaire was held with each woman alone in a waiting room and some cases in a follow-up clinic for 45 minute for the interview. Collection of data was from the control group who received routine care and the study group who received assessment and nursing intervention.

\section{Timing and Scheduling}

The number of sessions with the researcher was determined by the duration of chemotherapy treatment for each woman. The initial session with the researcher was scheduled for the baseline assessment. Successive sessions were planned during the previous session, most often attempting to keep the day and time similar. The flow of intervention was through 5 sessions (may be less) for women received a small number of doses with the average of one session every 3 weeks for 4 phases of the nursing intervention program (pre \& post). Figure 1 illustrates the flow of intervention for prescribed cycles of chemotherapy.

\section{Baseline assessment}

\section{Evaluation}

\section{Follow up assessment}

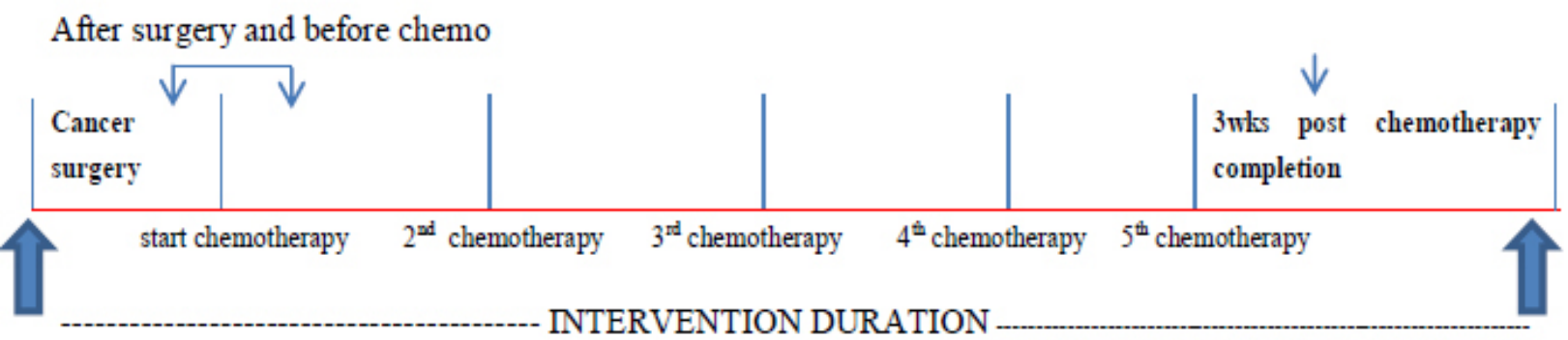

Fig1. timing of baseline and follow up assessment and health education intervention.

Data were collected through interviews, assessment, implementation, and follow up \& evaluation phases.

\section{i. Interviewing Phase}

The researcher briefly explained the aim of the study to women who meet the criteria for inclusion in the study. Through interviewing women, the researcher collected socio-demographic data, Obstetrical \& gynecological history, Sources of social stressors, Clinical characteristics. Interviewing was carried out during the initial visit using interviewing questionnaire, and each interview lasted for 15 minutes.

\section{ii. Assessment}

The baseline (pre-intervention) assessment was conducted prior to the initial chemotherapy cycles; follow-up was conducted during subsequent chemotherapy cycle, while evaluation (post-intervention) assessment was conducted 3 weeks after the last chemotherapy dose was received. Each session, the researcher recorded the side effects of chemotherapy after the previous dose (follow-up sheet). 
Survivorship in Women Undergoing Gynecological and Breast Cancer Treatment in Upper Egypt: The Impact of Quality of Life Improvement Educational Program

After obtaining interviewing data, in-depth assessment of symptoms related to gynecologic \& breast cancer and treatment-induced symptoms was carried out to women using the FSFI to assess sexual functioning during the past 4 weeks, and using the impact of events scale to assess traumatic stress reactions to cancer diagnosis and treatment, finally the TCHI FACT-G questionnaire was used to measure the impact of gynecologic \& breast cancer and related treatment on patients' QOL. In subsequent visits, the assessment was continued to assess a presence of any side effects by using oncology treatment side effects record. If complications discovered, referral to the physicians was carried out.

\section{iii. Implementation of QOL Improvement Education Program}

The researchers developed the QOL improvement educational program, after comprehensive reviewing of the relevant literature, based on the obtained baseline assessment data from assessment phase.

Women in the study group received tailored QOL improvement education program. The main components of the intervention program were, therefore, information provision related to knowledge of cancer, impacts of cancer treatment and self-care. Women were able to become familiar with the illness event and related symptoms, as well as received informational support and advice to solve a problem. Moreover, beliefs and values in sexuality and menopausal transition were clarified, health education on the psychological aspect, dietary advice, and exercise. Behavior therapy consisted of stress management, relaxation and deep breathing exercises, coping skills, and Kegel's exercises. Psychological support was solely provided in the form of counseling which focused on emotional support. The program carried out in the form of individualized health education sessions, while a handout was used to facilitate the process of education; each session took more than an hour. Any clarification needed for the women was given by the researcher. At the beginning of the initial session, an orientation of nursing intervention was taken place. Each session started with a summary of the previous one. To ensure exposure of all women to the same learning experience, all women received the nursing intervention content using simple teaching methods as discussion, demonstration, and re-demonstration. Suitable teaching aids specially prepared for the nursing intervention was used as printed materials and posters.

The researchers developed a printed booklet in Arabic language to fulfill needs, cover knowledge deficit and get the satisfaction of the participant women. It contained; (1) Introduction about breast and gynecologic cancer as definition, diagnosis, signs and symptoms to be monitored, an overview of treatment modalities and the most common side effects and the necessary nursing measures to manage it, (2) Quality of life and effect of gynecologic \& breast cancer on QOL, (3) Screening measures for prevention and early detection of metastasis to other organs as information about pap smear, mammogram, and breast self-examination. Each of this content was supported with suitable figures simple knowledge in Arabic language.

\section{iv. Follow up and Evaluation Phase}

Women were contacted in the day of visit in the Oncology Institute to be followed up after three weeks from initial visit and for an average of 5 times with three weeks interval and this was done by using follow up sheet (oncology treatment side effects record). Moreover, women were instructed to return the Oncology Institute at any time they experience any problems and referral system was carried out. An evaluation was applied after the program through the administration of follow-up questionnaires to measure the effectiveness of education program on QOL improvement.

\section{Data Analysis}

All the statistical analysis was performed using IBM SPSS package version 20. Collected data were coded and analyzed. The data were tested for normality using Anderson-Darling test and for homogeneity variances prior to further statistical analysis. 
Survivorship in Women Undergoing Gynecological and Breast Cancer Treatment in Upper Egypt: The Impact of Quality of Life Improvement Educational Program

i. Descriptive statistics for the variables were calculated.

a. Categorical variables were described by numbers and percentage.

b. Continuous variables were described by mean and standard deviation (Mean \pm SD).

ii. Inferential statistics:- All tests were used as tests of significance at p. value $<0.05$.

a. Chi-square $\left(x^{2}\right)$ test used to compare between categorical variables.

b. Mc-Namar test for repeated measure qualitative data.

c. Wilcoxon signed-rank test for non-parametric quantitative data within each group.

d. Non-parametric Spearman's rho correlation.

e. Pesarson correlation coefficient ( $\mathrm{r}$ ) used to assess the association between continuous scales.

iii. The graphical presentation included Column chart diagram.

\section{RESULTS}

Table (1) portrays women's characteristics. The age range of the sample was 21 to 55 years. Regarding women's general socio-demographic, obstetrical \& gynecological characteristics and sources of social stressors of both groups (gynecologicand breast cancer), no statistically significant difference was found which denotes homogeneity of the groups.

Figure (2) illustrates $64.0 \%$ of participants had breast cancer, while $36 \%$ of participants had gynecological cancer. The majority of the women had undergone gynecologic cancer treatment were had endometrial cancer $(47.2 \%)$ or utero-ovarian cancer $(41.7 \%)$, while $8.3 \%$ and $2.8 \%$ of them were had ovarian vulvar cancer.

Figure (3) illustrates, as more than three-quarters of the study group (77.7\%) vs. (61.1\%) of the control group were in the fourth stage of disease in gynecologic cancer group, while in breast cancer group $65.6 \%$ \& $56.2 \%$ of the study and control group, respectively, were in the fourth stage of disease. No statistically significant difference regarding stage of cancer.

Figure (4) demonstrates that, about one-third of the study group of breast cancer (34.4\%) Vs. (59.4\%) of the control group received surgical treatment, and chemotherapy, and another third (34.4\%) of the study group vs. $(28.1 \%)$ of the control group received surgical treatment, chemotherapy and radiotherapy. In gynecologic cancer, equally, more than one-third of the study group (38.9\%) received chemotherapy and the other third received surgical treatment and chemotherapy (33.3\%), while in the control group near to three quarters $(72.2 \%)$ received surgical treatment and chemotherapy. No statistically significant difference was found.

Table 2 illustrated the common complains of the women from treatment side effects prior to initiation and throughout period of therapy. In both breast and gynecologic cancer group, no statistically significant difference was found between study and control group.

It is clear in Table 3 that there is a highly statistical significant difference in relation to the impact of the health education program on sexual function in women with breast cancer as a trend towards improvement achieved in all subscales of sexual function index ( $\mathrm{p} \leq 0.001)$. Additionally, women with gynecologic cancer, no significant difference was found in sexual functioning between the study and control groups. The difference in the subscales in the two groups was also non-significant except a trend towards improvement achieved in the arousal function of the study group as it improved from $(1.6 \pm 1.6 \%)$ to $(2.9 \pm 1.9 \%),(p=0.041)$.

The effect of health education program on traumatic stress reactions to cancer diagnosis and treatment is illustrated in Table 4. It was obvious that the cases in the study group in both breast and gynecologic cancer 
Survivorship in Women Undergoing Gynecological and Breast Cancer Treatment in Upper Egypt: The Impact of Quality of Life Improvement Educational Program

had a highly statistically significant difference in relation to impact of the health education program on CSS (p $=0.001 \& 0.011$ ), respectively. Moreover, in relation to control groups, the same table reveals no statistically significant difference in neither breast nor gynecologic groups $(\mathrm{p}=0.324 \& 0.597)$, respectively.

Table1. Distribution of the studied women according to their characteristics.

\begin{tabular}{|c|c|c|c|c|c|c|c|c|c|c|}
\hline \multirow{3}{*}{ Women's Characteristics } & \multicolumn{5}{|c|}{ Breast group } & \multicolumn{5}{|c|}{ Gynecological group } \\
\hline & \multicolumn{2}{|c|}{$\begin{array}{c}\text { Study } \\
(n=32)\end{array}$} & \multicolumn{2}{|c|}{$\begin{array}{l}\text { Control } \\
(n=32)\end{array}$} & \multirow[t]{2}{*}{ P. value } & \multicolumn{2}{|c|}{$\begin{array}{c}\text { Study } \\
(\mathrm{n}=18)\end{array}$} & \multicolumn{2}{|c|}{$\begin{array}{l}\text { Control } \\
(n=18)\end{array}$} & \multirow{2}{*}{$\begin{array}{c}P . \\
\text { value }\end{array}$} \\
\hline & No. & $\%$ & No. & $\%$ & & No. & $\%$ & No. & $\%$ & \\
\hline \multicolumn{11}{|c|}{ Socio-demographic characteristics } \\
\hline Age & \multicolumn{2}{|c|}{$39.5 \pm 6.2$} & \multicolumn{2}{|c|}{$41.2 \pm 7.3$} & 0.304 & \multicolumn{2}{|c|}{$39.6 \pm 8.9$} & \multicolumn{2}{|c|}{$40.6 \pm 10.2$} & 0.742 \\
\hline \multicolumn{11}{|l|}{ Education } \\
\hline Illiterate & 15 & 46.9 & 14 & 43.8 & \multirow{4}{*}{0.509} & 10 & 55.6 & 11 & 61.1 & \multirow{4}{*}{0.715} \\
\hline Read and write & 6 & 18.8 & 6 & 18.8 & & 2 & 11.1 & 3 & 16.7 & \\
\hline Technical education & 6 & 18.8 & 10 & 31.3 & & 5 & 27.8 & 4 & 22.2 & \\
\hline Higher education & 5 & 15.6 & 2 & 6.3 & & 1 & 5.6 & 0 & 0.0 & \\
\hline \multicolumn{11}{|l|}{ Occupation } \\
\hline Working & 5 & 15.6 & 3 & 9.4 & \multirow{2}{*}{0.450} & 0 & 0.0 & 1 & 5.6 & \multirow{2}{*}{0.310} \\
\hline House wife & 27 & 84.4 & 29 & 90.6 & & 18 & 100.0 & 17 & 94.4 & \\
\hline \multicolumn{11}{|l|}{ Residence } \\
\hline Urban & 14 & 43.8 & 11 & 34.4 & \multirow{2}{*}{0.442} & 5 & 27.8 & 4 & 22.2 & \multirow{2}{*}{0.700} \\
\hline Rural & 18 & 56.3 & 21 & 65.6 & & 13 & 72.2 & 14 & 77.8 & \\
\hline \multicolumn{11}{|c|}{ Income (from their point of view) } \\
\hline Enough & 18 & 56.3 & 11 & 34.4 & \multirow{2}{*}{0.079} & 9 & 50.0 & 10 & 55.6 & \\
\hline Not enough & 14 & 43.7 & 21 & 65.6 & & 9 & 50.0 & 8 & 44.4 & 0.150 \\
\hline Obstetrical \& gynecologic & & & & & & & & & & \\
\hline Age at menarche & 13. & \pm 1.5 & 13. & +1.4 & 0.725 & 13. & \pm 1.4 & & 1.4 & 1.000 \\
\hline Cessation of menstrual & & & & & & & & & & \\
\hline Yes & 15 & 46.9 & 14 & 43.8 & 0562 & 11 & 61.1 & 15 & 83.3 & 0.137 \\
\hline No & 17 & 53.1 & 18 & 56.3 & 0.302 & 7 & 38.9 & 3 & 16.7 & ובנבי \\
\hline No. Of living children & 3.4 & 1.3 & & 1.5 & 0.068 & & \pm 1.5 & & & 0.566 \\
\hline Sources of social stressor & & & & & & & & & & \\
\hline Financial & & & & & & & & & & \\
\hline Yes & 3 & 9.4 & 8 & 25.0 & 0000 & 3 & 16.7 & 5 & 27.8 & 0423 \\
\hline No & 29 & 90.6 & 24 & 75.0 & 0.098 & 15 & 83.3 & 13 & 72.2 & $0.4 \angle 3$ \\
\hline Emotional ill & & & & & & & & & & \\
\hline Yes & 5 & 15.6 & 2 & 6.3 & 0.230 & 2 & 11.1 & 3 & 16.7 & 0.630 \\
\hline No & 27 & 84.4 & 30 & 93.8 & & 16 & 88.9 & 15 & 83.3 & 0.630 \\
\hline Chronic event & & & & & & & & & & \\
\hline Yes & 5 & 15.6 & 7 & 21.9 & 0.522 & 4 & 22.2 & 7 & 38.9 & 0278 \\
\hline No & 27 & 84.4 & 25 & 78.1 & & 14 & 77.8 & 11 & 61.1 & \\
\hline Problem related to drug i & & & & & & & & & & \\
\hline Yes & 6 & 18.8 & 6 & 18.8 & & 7 & 38.9 & 6 & 33.3 & \\
\hline No & 26 & 81.3 & 26 & 81.3 & 1.000 & 11 & 61.1 & 12 & 66.7 & 0.729 \\
\hline
\end{tabular}

Chi-square test for quantitative data between the two groups* Statistically significant difference $(p<0.05)$ 
Survivorship in Women Undergoing Gynecological and Breast Cancer Treatment in Upper Egypt: The Impact of Quality of Life Improvement Educational Program

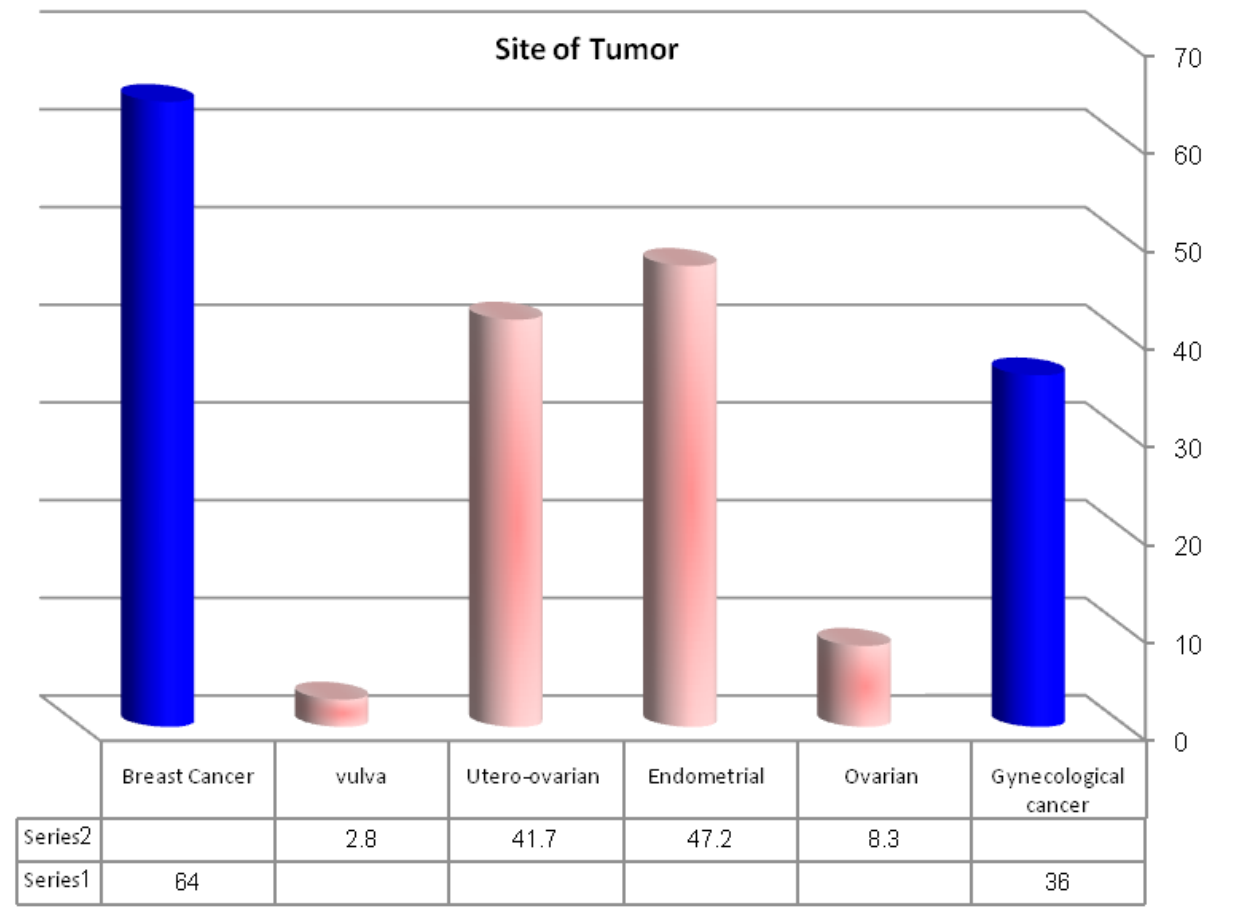

Fig2. Distribution of the studied women according to their clinical Site of Tumor

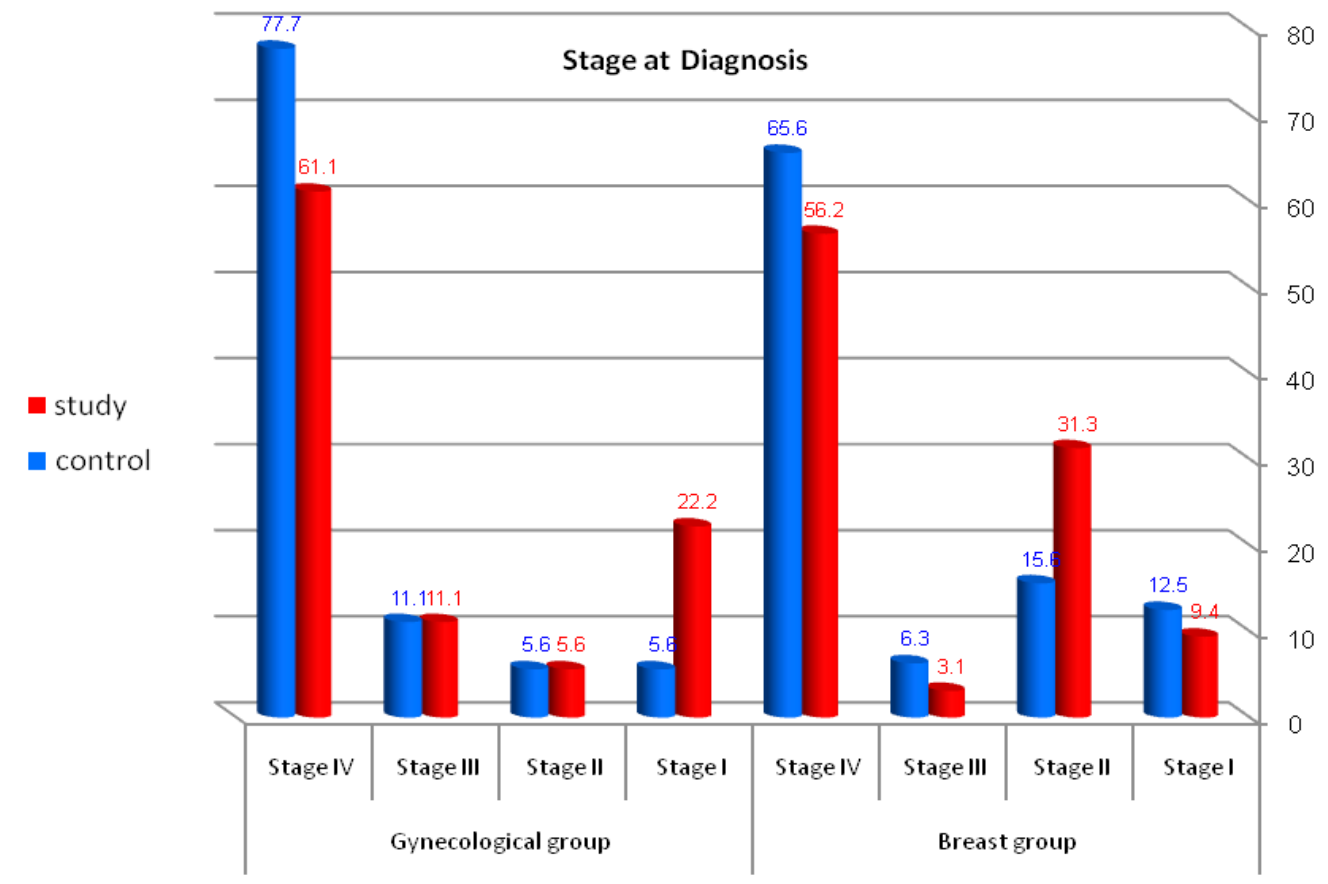

Fig3. Distribution of the studied women according to their clinical Stage at diagnosis 
Survivorship in Women Undergoing Gynecological and Breast Cancer Treatment in Upper Egypt: The Impact of Quality of Life Improvement Educational Program

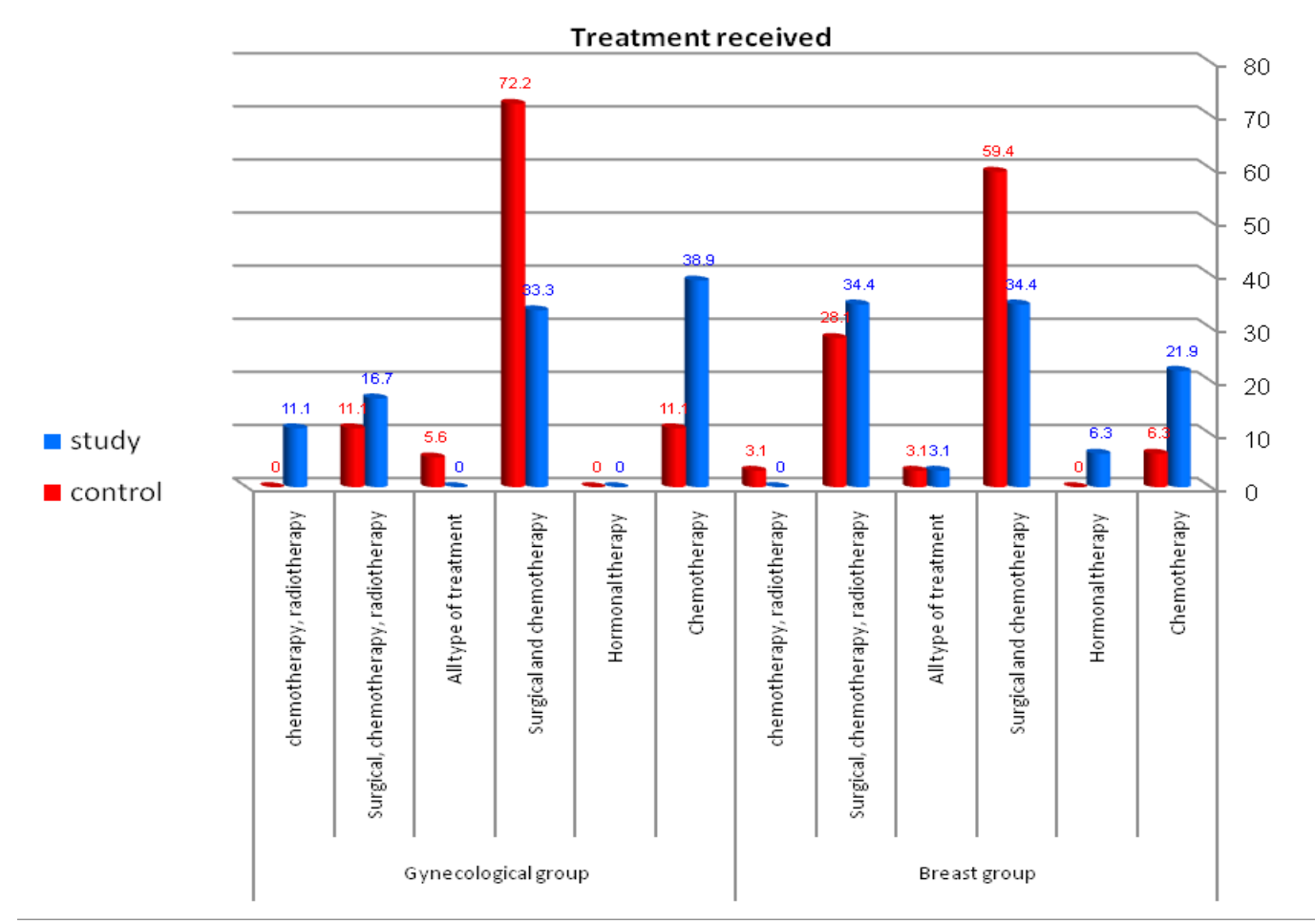

Fig4. Distribution of the studied women according to their clinical Treatment received

It is obvious from Table (5) that, there is a highly statistically significant difference in the study groups of both breast and gynecologic groups in relation to impact of the health education program on the total score of QOL, and at all domains, (except emotional wellbeing), of QOL at initial and last session ( $\mathrm{p} \leq 0.001)$. On the other side in the control groups, there was no significantly difference at any domains of QOL at initial and last session (p $>0.05$ ).

Table 6 shows the relationship between characteristics of the studied women and their sexual function, CSS, and QOL. As regards study groups, there is no significant effect of demographic data on female sexual function or CSS or QOL of breast cancer women. Although, gynecologic cancer women, pre-administration of the program, the age, and age at menarche are the most significant predictor of female sexual function $(p=0.037,0.042) \&$ (beta $=-1.285,0.670)$, respectively. While occupation was the most significant predictor of CSS post-administration of the program $(\mathrm{p}=0.0006) \&($ beta $=-0.611)$.

It is clear from Table 7 that there is no significant effect of complains of cancer treatment on female sexual function as regards study of both breast and gynecological cancer patients except on study group of breast cancer (post administration of the program) the psychosomatic symptoms were the most significant predictor of complaints after initial dose and throughout the treatment on female sexual function ( $p=0.035)$, and affected negatively (beta $=-0.465$ ). In relation to women with breast and gynecological cancer, there is no significant effect of complaints of cancer treatment on QOL with regard to breast cancer study groups, but in gynecologic study group (post administration of the program) regarding complaints after the initial dose and throughout the treatment, the psychosomatic symptoms were the most significant predictor $(\mathrm{p}=0.027,0.000)$, respectively, (beta $=-0.140,0.407$ ), respectively.

Regarding to the relationship between CSS and QOL, Table 8 shows a significant relationship in study group with breast cancer pre and post-administration of the program on the all domains, and the entire QOL except on 
Survivorship in Women Undergoing Gynecological and Breast Cancer Treatment in Upper Egypt: The Impact of Quality of Life Improvement Educational Program

emotional well-being (posttest), $(\mathrm{p}<0.05) \&(\mathrm{r}=$ correlated positively). In relation to women with gynecologic cancer, there was a significant relationship between CSS, Physical, social well-being, and the entire QOL pre-administration of the program ( $\mathrm{p}<0.05)$, ( $\mathrm{r}=$ correlated positively). While after administration of the program, there was a significant relationship between CSS, emotional, and social well-being $(\mathrm{p}<0.05),(\mathrm{r}=$ correlated positively).

Table2. Distribution of the studied women according to their Complains from treatment side effects

\begin{tabular}{|c|c|c|c|c|c|c|c|c|c|c|}
\hline \multirow{3}{*}{\begin{tabular}{|ll} 
Complains from treatment side effects & Group \\
\end{tabular}} & \multicolumn{5}{|c|}{ Breast group } & \multicolumn{5}{|c|}{ Gynecological group } \\
\hline & \multicolumn{2}{|c|}{$\begin{array}{c}\text { Study (n = } \\
\text { 32) }\end{array}$} & \multicolumn{2}{|c|}{$\begin{array}{l}\text { Control (n } \\
=32)\end{array}$} & \multirow{2}{*}{$\begin{array}{c}\text { P. } \\
\text { value }\end{array}$} & \multicolumn{2}{|c|}{$\begin{array}{c}\text { Study (n = } \\
18)\end{array}$} & \multicolumn{2}{|c|}{$\begin{array}{l}\text { Control (n } \\
=18)\end{array}$} & \multirow{2}{*}{$\begin{array}{c}\text { P. } \\
\text { value }\end{array}$} \\
\hline & No. & $\%$ & No. & $\%$ & & No. & $\%$ & No. & $\%$ & \\
\hline \multicolumn{11}{|l|}{ Complain before starting of dose } \\
\hline No complain & 8 & 25.0 & 5 & 15.6 & \multirow{10}{*}{0.198} & 2 & 11.1 & 2 & 11.1 & \multirow{10}{*}{0.764} \\
\hline Bleeding & 0 & 0.0 & 1 & 3.1 & & 7 & 38.9 & 6 & 33.3 & \\
\hline $\begin{array}{l}\text { Pain, burning sensation, stomach pain ,loss of appetite, vomiting, } \\
\text { bad psychological status }\end{array}$ & 0 & 0.0 & 1 & 3.1 & & 0 & 0.0 & 0 & 0.0 & \\
\hline Offensive discharge from vagina, low back pain, tingling sensation & 0 & 0.0 & 0 & 0.0 & & 2 & 11.1 & 2 & 11.1 & \\
\hline Breast mass, pain, mastitis, shoulder pain & 21 & 65.6 & 19 & 59.4 & & 2 & 11.1 & 1 & 5.6 & \\
\hline psychosomatic symptoms & 1 & 3.1 & 4 & 12.5 & & 2 & 11.1 & 3 & 16.7 & \\
\hline $\begin{array}{l}\text { Vomiting, nausea, knee pain, dyspnea, cough, bad psychological } \\
\text { status }\end{array}$ & 0 & 0.0 & 2 & 6.3 & & 0 & 0.0 & 1 & 5.6 & \\
\hline Pain in the body & 0 & 0.0 & 0 & 0.0 & & 2 & 11.1 & 0 & 0.0 & \\
\hline $\begin{array}{l}\text { Nausea, dizziness, fatigue, headache, pain, hair loss, fever, } \\
\text { diarrhea, loss of appetite, bloating }\end{array}$ & 2 & 6.3 & 0 & 0.0 & & 1 & 5.6 & 2 & 11.1 & \\
\hline Deterioration & 0 & 0.0 & 0 & 0.0 & & 0 & 0.0 & 1 & 5.6 & \\
\hline \multicolumn{11}{|l|}{ Complains after first dose and throughout the treatment } \\
\hline psychosomatic symptoms & 2 & 6.3 & 8 & 25.0 & \multirow{6}{*}{0.142} & 2 & 11.1 & 3 & 16.7 & \multirow{6}{*}{0.753} \\
\hline $\begin{array}{l}\text { Continuous pain in leg, weakness, loss of balance, headache, hair } \\
\text { loss }\end{array}$ & 0 & 0.0 & 1 & 3.1 & & 0 & 0.0 & 0 & 0.0 & \\
\hline $\begin{array}{l}\text { Vomiting, nausea, knee pain, dyspnea, cough, bad psychological } \\
\text { status }\end{array}$ & 1 & 3.1 & 1 & 3.1 & & 1 & 5.6 & 1 & 5.6 & \\
\hline Pain in the body & 0 & 0.0 & 0 & 0.0 & & 1 & 5.6 & 0 & 0.0 & \\
\hline $\begin{array}{l}\text { Nausea, dizziness, fatigue, headache, pain, hair loss, fever, } \\
\text { diarrhea, loss of appetite }\end{array}$ & 29 & 90.6 & 21 & 65.6 & & 14 & 77.8 & 14 & 77.8 & \\
\hline Colicky pain, constipation, headache, knee pain & 0 & 0.0 & 1 & 3.1 & & 0 & 0.0 & 0 & 0.0 & \\
\hline \multicolumn{11}{|l|}{ Complain after completion of doses } \\
\hline No complain & 3 & 9.4 & 4 & 12.5 & \multirow{11}{*}{0.205} & 3 & 16.7 & 1 & 5.6 & \multirow{11}{*}{0.122} \\
\hline Loss of weight & 0 & 0.0 & 0 & 0.0 & & 1 & 5.6 & 0 & 0.0 & \\
\hline Vomiting & 0 & 0.0 & 1 & 3.1 & & 0 & 0.0 & 0 & 0.0 & \\
\hline Breast mass & 0 & 0.0 & 4 & 12.5 & & 0 & 0.0 & 0 & 0.0 & \\
\hline psychosomatic symptoms & 24 & 75.0 & 17 & 53.1 & & 10 & 55.6 & 6 & 33.3 & \\
\hline $\begin{array}{l}\text { Continuous pain in leg, weakness, loss of balance, headache, hair } \\
\text { loss }\end{array}$ & 0 & 0.0 & 1 & 3.1 & & 0 & 0.0 & 2 & 11.1 & \\
\hline Headache, leg pain & 0 & 0.0 & 1 & 3.1 & & 1 & 5.6 & 0 & 0.0 & \\
\hline $\begin{array}{l}\text { Vomiting, nausea, knee pain, dyspnea, cough, bad psychological } \\
\text { status }\end{array}$ & 1 & 3.1 & 1 & 3.1 & & 0 & 0.0 & 3 & 16.7 & \\
\hline Pain in the body & 1 & 3.1 & 1 & 3.1 & & 1 & 5.6 & 0 & 0.0 & \\
\hline $\begin{array}{l}\text { Nausea, dizziness, fatigue, headache, pain, hair loss, fever, } \\
\text { diarrhea, loss of appetite }\end{array}$ & 3 & 9.4 & 0 & 0.0 & & 2 & 11.1 & 3 & 16.7 & \\
\hline Deterioration & 0 & 0.0 & 2 & 6.3 & & 0 & 0.0 & 3 & 16.7 & \\
\hline \multicolumn{11}{|l|}{ Compliance to chemotherapy and other treatment cycles } \\
\hline Yes & 32 & 100.0 & 32 & 100.0 & & 18 & 100.0 & 18 & 100.0 & \\
\hline No & 0 & 0.0 & 0 & 0.0 & & 0 & 0.0 & 0 & 0.0 & \\
\hline
\end{tabular}

\# More than one option was checked. Chi-square test $\quad *$ Statistically significant difference $(p<0.05)$ 
Survivorship in Women Undergoing Gynecological and Breast Cancer Treatment in Upper Egypt: The Impact of Quality of Life Improvement Educational Program

Table3. Distribution of the studied women according to sexual functions of the studied women with breast and gynecological cancer in the Study and Control Group at initial and follow-up session

\begin{tabular}{|c|c|c|c|c|c|c|c|c|c|c|c|c|}
\hline \multirow{3}{*}{$\begin{array}{l}\text { Group } \\
\text { Sexual } \\
\text { Functions }\end{array}$} & \multicolumn{6}{|c|}{ Breast } & \multicolumn{6}{|c|}{ Gynecological } \\
\hline & \multicolumn{3}{|c|}{ Study } & \multicolumn{3}{|c|}{ Control } & \multicolumn{3}{|c|}{ Study } & \multicolumn{3}{|c|}{ Control } \\
\hline & Pre & Post & P. value & Pre & Post & $\begin{array}{c}P . \\
\text { value }\end{array}$ & Pre & Post & $\begin{array}{c}\text { P. } \\
\text { value }\end{array}$ & Pre & Post & P. value \\
\hline Desire & $1.9 \pm 1.2$ & $3.1 \pm 1.2$ & $<0.001^{* * *}$ & $2.2 \pm 1.5$ & $2.1 \pm 1.5$ & 0.765 & $1.7 \pm 1.4$ & $2.3 \pm 1.4$ & 0.239 & $1.6 \pm 1.3$ & $1.3 \pm 1.1$ & 0.502 \\
\hline Arousal & $1.8 \pm 1.6$ & $3.6 \pm 1.5$ & $<0.001^{* * *}$ & $1.8 \pm 1.7$ & $1.9 \pm 1.8$ & 0.800 & $1.6 \pm 1.6$ & $2.9 \pm 1.9$ & $0.041^{*}$ & $1.5 \pm 1.8$ & $0.9 \pm 1.2$ & 0.244 \\
\hline Lubrication & $2.4 \pm 2.4$ & $4.6 \pm 1.7$ & $<0.001^{* * *}$ & $2.6 \pm 2.3$ & $2.6 \pm 2.3$ & 1.000 & $2.6 \pm 2.2$ & $3.6 \pm 2.2$ & 0.170 & $1.6 \pm 2.1$ & $1.2 \pm 1.6$ & 0.500 \\
\hline Orgasm & $2 \pm 2$ & $4.2 \pm 1.6$ & $<0.001^{* * *}$ & $2.3 \pm 2.1$ & $2.3 \pm 2.2$ & 0.945 & $2.1 \pm 2$ & $3.3 \pm 2.2$ & 0.104 & $1.5 \pm 1.9$ & $1.1 \pm 1.4$ & 0.453 \\
\hline Satisfaction & $2.2 \pm 2.2$ & $3.9 \pm 1.8$ & $<0.001^{* * *}$ & $2 \pm 1.8$ & $2.3 \pm 2.2$ & 0.585 & $2.2 \pm 2.1$ & $3.2 \pm 2.1$ & 0.142 & $1.5 \pm 1.9$ & $1 \pm 1.4$ & 0.325 \\
\hline Pain & $2.7 \pm 0.9$ & $1.8 \pm 1.7$ & $0.008^{* *}$ & $1.8 \pm 1.5$ & $1.8 \pm 1.6$ & 0.948 & $2.3 \pm 1.4$ & $1.8 \pm 1.6$ & 0.349 & $1.5 \pm 1.9$ & $1.4 \pm 2$ & 0.890 \\
\hline FSD \# & $12.1 \pm 10.4$ & $22.1 \pm 8.1$ & $<0.001 * * *$ & $\begin{array}{c}12.6 \pm \\
10.5\end{array}$ & $\begin{array}{c}12.9 \pm \\
11.1\end{array}$ & 0.901 & $\begin{array}{l}12 \pm \\
10.1\end{array}$ & $\begin{array}{c}17.6 \pm \\
10.6\end{array}$ & 0.118 & $\begin{array}{l}9.2 \pm \\
10.3\end{array}$ & $6.9 \pm 7.8$ & 0.439 \\
\hline
\end{tabular}

Wilcoxon Signed rank test for non-parametric quantitative data within each group

(\#) McNamar test for repeated measure qualitative data.

${ }^{*} P<0.05$ mild Statistical significant.

** $P<0.01$ moderate Statistical significance.

${ }^{* * *} P<0.001$ highly Statistical significant.

Table4. Distribution of the studied women with breast cancer in the Study and Control Group According to CSS at initial and follow-up session

\begin{tabular}{|c|c|c|c|c|c|c|c|c|c|c|c|c|c|c|c|c|c|c|c|c|}
\hline \multirow{4}{*}{ CSS \# } & \multicolumn{10}{|c|}{ Breast $($ No. $=64)$} & \multicolumn{10}{|c|}{ Gynecological (No. = 36) } \\
\hline & \multicolumn{4}{|c|}{ Study (No. $=32$ ) } & \multirow{3}{*}{ P. value } & \multicolumn{4}{|c|}{ Control (No.= 32) } & \multirow{3}{*}{$\begin{array}{c}\text { P. } \\
\text { value }\end{array}$} & \multicolumn{4}{|c|}{ Study (No.= 18) } & \multirow{3}{*}{ P. value } & \multicolumn{4}{|c|}{ Control (No.= 18) } & \multirow{3}{*}{$\begin{array}{c}\text { P. } \\
\text { value }\end{array}$} \\
\hline & \multicolumn{2}{|c|}{ Pre } & \multicolumn{2}{|c|}{ Post } & & \multicolumn{2}{|c|}{ Pre } & \multicolumn{2}{|c|}{ Post } & & \multicolumn{2}{|c|}{ Pre } & \multicolumn{2}{|c|}{ Post } & & \multicolumn{2}{|c|}{ Pre } & \multicolumn{2}{|c|}{ Post } & \\
\hline & No. & $\%$ & No. & $\%$ & & No. & $\%$ & No. & $\%$ & & No. & $\%$ & No. & $\%$ & & No. & $\%$ & No. & $\%$ & \\
\hline No & 2 & 6.3 & 13 & 40.6 & \multirow{4}{*}{$0.001^{* * *}$} & 3 & 9.4 & 4 & 12.5 & \multirow{4}{*}{0.324} & 2 & 11.1 & 10 & 55.6 & \multirow{4}{*}{$0.011^{* *}$} & 0 & 0.0 & 1 & 5.6 & \multirow{4}{*}{0.597} \\
\hline $\begin{array}{l}\text { Mild post- } \\
\text { traumatic stress } \\
\text { disorder [PTSD] }\end{array}$ & 3 & 9.4 & 9 & 28.1 & & 2 & 6.3 & 6 & 18.8 & & 3 & 16.7 & 3 & 16.7 & & 3 & 16.7 & 3 & 16.7 & \\
\hline $\begin{array}{l}\text { Moderate } \\
\text { [PTSD] }\end{array}$ & 1 & 3.1 & 5 & 15.6 & & 1 & 3.1 & 0 & 0.0 & & 0 & 0.0 & 1 & 5.6 & & 0 & 0.0 & 2 & 11.1 & \\
\hline Severe [PTSD] & 26 & 81.3 & 5 & 15.6 & & 26 & 81.3 & 22 & 68.8 & & 13 & 72.2 & 4 & 22.2 & & 15 & 83.3 & 12 & 66.7 & \\
\hline
\end{tabular}

Wilcoxon Signed rank test for non-parametric quantitative data within each group

(\#)McNamar test for repeated measure qualitative data.

** $P<0.01$ moderate Statistical significance.
${ }^{*} P<0.05$ mild Statistical significant. ${ }^{* * *} P<0.001$ highly Statistical significant. 
Survivorship in Women Undergoing Gynecological and Breast Cancer Treatment in Upper Egypt: The Impact of Quality of Life Improvement Educational Program

Table5. Distribution of the studied women with gynecological and breast cancer in the study and control group according to cancer QOL at first and last session.

\begin{tabular}{|c|c|c|c|c|c|c|c|c|c|c|c|c|c|c|c|c|c|c|c|c|}
\hline \multirow{4}{*}{$\begin{array}{l}\text { Group } \\
\text { QOL Items }\end{array}$} & \multicolumn{10}{|c|}{ Breast $($ No. $=64)$} & \multicolumn{10}{|c|}{ Gynecological (No. $=36)$} \\
\hline & \multicolumn{4}{|c|}{ Study (No.= 32) } & \multirow{3}{*}{ P. value } & \multicolumn{4}{|c|}{ Control $($ No. $=32)$} & \multirow{3}{*}{$\begin{array}{c}\text { P. } \\
\text { value }\end{array}$} & \multicolumn{4}{|c|}{ Study (No.= 18) } & \multirow{3}{*}{ P. value } & \multicolumn{4}{|c|}{ Control $($ No. $=18)$} & \multirow{3}{*}{$\begin{array}{c}\text { P. } \\
\text { value }\end{array}$} \\
\hline & \multicolumn{2}{|c|}{ Pre } & \multicolumn{2}{|c|}{ Post } & & \multicolumn{2}{|c|}{ Pre } & \multicolumn{2}{|c|}{ Post } & & \multicolumn{2}{|c|}{ Pre } & \multicolumn{2}{|c|}{ Post } & & \multicolumn{2}{|c|}{ Pre } & \multicolumn{2}{|c|}{ Post } & \\
\hline & No. & $\%$ & No. & $\%$ & & No. & $\%$ & No. & $\%$ & & No. & $\%$ & No. & $\%$ & & No. & $\%$ & No. & $\%$ & \\
\hline \multicolumn{21}{|c|}{ Physical well-being } \\
\hline Poor & 18 & 56.3 & 3 & 9.4 & \multirow{3}{*}{$0.001^{* * *}$} & 18 & 56.3 & 16 & 50.0 & \multirow{3}{*}{0.517} & 10 & 55.6 & 2 & 11.1 & \multirow{3}{*}{$0.001^{* * *}$} & 12 & 66.7 & 15 & 83.3 & \multirow{3}{*}{0.465} \\
\hline Moderate & 11 & 34.4 & 8 & 25.0 & & 8 & 25.0 & 12 & 37.5 & & 6 & 33.3 & 1 & 5.6 & & 3 & 16.7 & 2 & 11.1 & \\
\hline Good & 3 & 9.4 & 21 & 65.6 & & 6 & 18.8 & 4 & 12.5 & & 2 & 11.1 & 15 & 83.3 & & 3 & 16.7 & 1 & 5.6 & \\
\hline \multicolumn{21}{|c|}{ Emotional well-being } \\
\hline Poor & 2 & 6.3 & 0 & 0.0 & & 6 & 18.8 & 5 & 15.6 & & 3 & 16.7 & 3 & 16.7 & & 4 & 22.2 & 5 & 27.8 & \\
\hline Moderate & 10 & 31.3 & 7 & 21.9 & 0.214 & 7 & 21.9 & 10 & 31.3 & 0.694 & 4 & 22.2 & 2 & 11.1 & 0.659 & 4 & 22.2 & 3 & 16.7 & 0.881 \\
\hline Good & 20 & 62.5 & 25 & 78.1 & & 19 & 59.4 & 17 & 53.1 & & 11 & 61.1 & 13 & 72.2 & & 10 & 55.6 & 10 & 55.6 & \\
\hline Social well-be & & & & & & & & & & & & & & & & & & & & \\
\hline Poor & 11 & 34.4 & 1 & 3.1 & & 4 & 12.5 & 10 & 31.3 & & 6 & 33.3 & 0 & 0.0 & & 4 & 22.2 & 8 & 44.4 & \\
\hline Moderate & 12 & 37.5 & 11 & 34.4 & $0.002^{* *}$ & 20 & 62.5 & 12 & 37.5 & 0.091 & 8 & 44.4 & 4 & 22.2 & $0.002^{* *}$ & 10 & 55.6 & 5 & 27.8 & 0.211 \\
\hline Good & 9 & 28.1 & 20 & 62.5 & & 8 & 25.0 & 10 & 31.3 & & 4 & 22.2 & 14 & 77.8 & & 4 & 22.2 & 5 & 27.8 & \\
\hline Functional we & bein & & & & & & & & & & & & & & & & & & & \\
\hline Poor & 19 & 59.4 & 2 & 6.3 & & 12 & 37.5 & 11 & 34.4 & & 11 & 61.1 & 1 & 5.6 & & 10 & 55.6 & 13 & 72.2 & \\
\hline Moderate & 12 & 37.5 & 14 & 43.8 & $0.001^{* * *}$ & 19 & 59.4 & 20 & 62.5 & 0.966 & 7 & 38.9 & 6 & 33.3 & $0.001^{* * *}$ & 4 & 22.2 & 5 & 27.8 & 0.105 \\
\hline Good & 1 & 3.1 & 16 & 50.0 & & 1 & 3.1 & 1 & 3.1 & & 0 & 0.0 & 11 & 61.1 & & 4 & 22.2 & 0 & 0.0 & \\
\hline Additional co & rnsr & elatec & to $d$ & diseas & & & & & & & & & & & & & & & & \\
\hline Poor & 13 & 40.6 & 0 & 0.0 & & 5 & 15.6 & 8 & 25.0 & & 5 & 27.8 & 0 & 0.0 & & 4 & 22.2 & 3 & 16.7 & \\
\hline Moderate & 14 & 43.8 & 12 & 37.5 & $0.001^{* * *}$ & 25 & 78.1 & 22 & 68.8 & 0.643 & 13 & 72.2 & 7 & 38.9 & $0.001^{* * *}$ & 13 & 72.2 & 15 & 83.3 & 0.526 \\
\hline Good & 5 & 15.6 & 20 & 62.5 & & 2 & 6.3 & 2 & 6.3 & & 0 & 0.0 & 11 & 61.1 & & 1 & 5.6 & 0 & 0.0 & \\
\hline Total Score Q & & & & & & & & & & & & & & & & & & & & \\
\hline Poor & 5 & 15.6 & 0 & 0.0 & & 7 & 21.9 & 8 & 25.0 & & 2 & 11.1 & 0 & 0.0 & & 2 & 11.1 & 6 & 33.3 & \\
\hline Moderate & 23 & 71.9 & 11 & 34.4 & $0.001^{* * *}$ & 23 & 71.9 & 22 & 68.8 & 0.957 & 16 & 88.9 & 4 & 22.2 & $0.001^{* * *}$ & 14 & 77.8 & 12 & 66.7 & 0.125 \\
\hline Good & 4 & 12.5 & 21 & 65.6 & & 2 & 6.3 & 2 & 6.3 & & 0 & 0.0 & 14 & 77.8 & & 2 & 11.1 & 0 & 0.0 & \\
\hline
\end{tabular}

Wilcoxon Signed rank test for non-parametric quantitative data within each group.

$* P<0.05$ mild Statistical significant. $\quad * * \quad P<0.01$ moderate Statistical significance.

$* * * P<0.001$ highly Statistical significant.

American Research Journal of Gynaecology

Page 15 
Survivorship in Women Undergoing Gynecological and Breast Cancer Treatment in Upper Egypt: The Impact of Quality of Life Improvement Educational Program

Table6. The relationship between characteristics of the studied women (independent) and their sexual function, CSS, and QOL (dependent)

\begin{tabular}{|c|c|c|c|c|c|c|c|c|c|c|c|c|c|c|c|c|}
\hline \multirow[b]{4}{*}{ Women'sCharacteristics } & \multicolumn{8}{|c|}{ Breast } & \multicolumn{8}{|c|}{ Gynecological } \\
\hline & \multicolumn{4}{|c|}{ Study } & \multicolumn{4}{|c|}{ Control } & \multicolumn{4}{|c|}{ Study } & \multicolumn{4}{|c|}{ Control } \\
\hline & \multicolumn{2}{|c|}{ Pre } & \multicolumn{2}{|c|}{ Post } & \multicolumn{2}{|c|}{ Pre } & \multicolumn{2}{|c|}{ Post } & \multicolumn{2}{|c|}{ Pre } & \multicolumn{2}{|c|}{ Post } & \multicolumn{2}{|c|}{ Pre } & \multicolumn{2}{|c|}{ Post } \\
\hline & Beta & $\begin{array}{c}P . \\
\text { value }\end{array}$ & Beta & $\begin{array}{c}P . \\
\text { value }\end{array}$ & Beta & P. value & Beta & P. value & Beta & P. value & Beta & P. value & Beta & P. value & Beta & P. value \\
\hline \multicolumn{17}{|l|}{ Female Sexual Function } \\
\hline Age & -0.119 & 0.687 & 0.264 & 0.371 & -0.033 & 0.910 & 0.065 & 0.805 & -1.285 & $0.037^{*}$ & -0.946 & 0.206 & -0.094 & 0.945 & 1.784 & 0.069 \\
\hline Education & -0.281 & 0.424 & -0.394 & 0.257 & -0.580 & 0.150 & -0.058 & 0.866 & 1.044 & 0.140 & 0.876 & 0.363 & 0.391 & 0.699 & 0.808 & 0.209 \\
\hline Occupation (working) & 0.007 & 0.978 & 0.013 & 0.958 & 0.463 & 0.076 & 0.394 & 0.101 & 0.007 & 0.978 & 0.013 & 0.958 & -0.111 & 0.812 & 0.116 & 0.632 \\
\hline Age at menarche & 0.019 & 0.948 & 0.439 & 0.129 & 0.238 & 0.241 & -0.033 & 0.860 & 0.670 & $0.042^{*}$ & 0.765 & 0.089 & -0.028 & 0.946 & 0.200 & 0.433 \\
\hline Residence (urban) & -0.146 & 0.646 & -0.476 & 0.140 & 0.378 & 0.301 & -0.066 & 0.815 & 0.669 & 0.167 & 0.241 & 0.706 & 0.086 & 0.916 & -0.212 & 0.612 \\
\hline Income (enough) & 0.255 & 0.360 & 0.368 & 0.118 & 0.095 & 0.765 & 0.476 & 0.113 & 0.589 & 0.500 & 0.541 & 0.674 & -0.399 & 0.283 & 0.002 & 0.994 \\
\hline $\begin{array}{l}\text { cessation of menstruation } \\
\text { (yes) }\end{array}$ & 0.446 & 0.083 & -0.064 & 0.775 & -0.003 & 0.990 & -0.116 & 0.612 & 0.165 & 0.503 & 0.498 & 0.214 & -0.322 & 0.738 & -2.075 & $0.012^{*}$ \\
\hline No. of living children & 0.348 & 0.262 & -0.282 & 0.402 & -0.041 & 0.872 & 0.100 & 0.678 & 0.003 & 0.994 & 0.384 & 0.480 & 0.141 & 0.839 & 0.275 & 0.518 \\
\hline \multicolumn{17}{|l|}{ Cancer Specific Stress } \\
\hline Age & -0.224 & 0.414 & 0.037 & 0.913 & 0.146 & 0.583 & -0.030 & 0.922 & 0.128 & 0.866 & 1.466 & 0.118 & 2.330 & 0.177 & -0.071 & 0.954 \\
\hline Education & -0.178 & 0.581 & -0.105 & 0.789 & 0.239 & 0.495 & 0.218 & 0.595 & -1.064 & 0.331 & -0.901 & 0.420 & 2.359 & 0.085 & -1.287 & 0.213 \\
\hline Occupation (working) & -0.067 & 0.777 & -0.284 & 0.333 & -0.716 & $0.004^{* *}$ & -0.052 & 0.626 & -0.199 & 0.238 & -0.611 & $0.006^{* *}$ & 0.655 & 0.245 & -0.322 & 0.422 \\
\hline Age at menarche & 0.221 & 0.401 & 0.224 & 0.490 & -0.223 & 0.217 & -0.276 & 0.215 & 0.119 & 0.774 & -0.203 & 0.640 & 0.228 & 0.616 & 0.067 & 0.865 \\
\hline Residence (urban) & 0.180 & 0.539 & 0.046 & 0.898 & -0.536 & 0.107 & -0.108 & 0.748 & 0.620 & 0.409 & 0.516 & 0.502 & -1.489 & 0.154 & 0.232 & 0.727 \\
\hline Income (enough) & 0.082 & 0.747 & -0.278 & 0.297 & 0.314 & 0.274 & -0.237 & 0.493 & -0.530 & 0.714 & -1.135 & 0.464 & -0.398 & 0.324 & -0.162 & 0.631 \\
\hline $\begin{array}{l}\text { cessation of menstrual } \\
\text { (yes) }\end{array}$ & -0.128 & 0.575 & 0.036 & 0.888 & -0.309 & 0.164 & 0.055 & 0.840 & 0.677 & 0.149 & -0.089 & 0.832 & $\mid-1.515$ & 0.201 & 0.358 & 0.667 \\
\hline No. of living children & -0.448 & 0.124 & -0.074 & 0.848 & 0.023 & 0.920 & 0.166 & 0.563 & -0.087 & 0.884 & -0.707 & 0.290 & -0.844 & 0.304 & -0.879 & 0.233 \\
\hline \multicolumn{17}{|l|}{ Quality of life } \\
\hline Age & -0.185 & 0.546 & 0.059 & 0.853 & -0.279 & 0.264 & -0.273 & 0.353 & 0.428 & 0.689 & 0.505 & 0.668 & -0.402 & 0.789 & 0.722 & 0.349 \\
\hline Education & 0.215 & 0.554 & 0.026 & 0.944 & 0.269 & 0.413 & 0.325 & 0.400 & 0.015 & 0.991 & 0.373 & 0.814 & 0.545 & 0.623 & 1.253 & 0.070 \\
\hline Occupation (working) & 0.038 & 0.885 & -0.234 & 0.397 & -0.318 & 0.138 & 0.035 & 0.796 & -0.211 & 0.358 & -0.287 & 0.124 & 0.144 & 0.777 & 0.324 & 0.200 \\
\hline Age at menarche & 0.082 & 0.780 & 0.100 & 0.744 & -0.198 & 0.241 & 0.020 & 0.921 & -0.079 & 0.891 & -0.390 & 0.549 & -0.534 & 0.268 & -0.406 & 0.133 \\
\hline Residence (urban) & 0.171 & 0.605 & 0.029 & 0.933 & 0.103 & 0.732 & -0.120 & 0.703 & 0.069 & 0.945 & -0.054 & 0.961 & 0.030 & 0.974 & -1.390 & $0.019 *$ \\
\hline Income (enough) & 0.052 & 0.857 & -0.240 & 0.342 & -0.461 & 0.093 & -0.523 & 0.116 & -0.160 & 0.937 & -0.302 & 0.892 & 0.100 & 0.790 & -0.259 & 0.227 \\
\hline $\begin{array}{l}\text { cessation of menstrual } \\
\text { (yes) }\end{array}$ & -0.128 & 0.618 & -0.002 & 0.992 & 0.158 & 0.438 & 0.313 & 0.225 & 0.535 & 0.373 & -0.210 & 0.738 & 0.273 & 0.795 & 0.130 & 0.788 \\
\hline No. of living children & - 0.368 & 0.253 & 0.187 & 0.609 & 0.179 & 0.400 & -0.050 & 0.852 & 0.419 & 0.621 & 0.063 & 0.945 & 1.130 & 0.186 & -0.723 & 0.119 \\
\hline
\end{tabular}

Non-parametric Spearman's rho correlation * $P<0.05$ mild Statistical significant.

${ }^{* *} P<0.01$ moderate Statistical significance. ${ }^{* * *} P<0.001$ highly Statistical significant.

American Research Journal of Gynaecology

Page 16 
Survivorship in Women Undergoing Gynecological and Breast Cancer Treatment in Upper Egypt: The Impact of Quality of Life Improvement Educational Program

Table7. Multiple regression analysis between complains of cancer treatment (independents) and women's sexual function, CSS and QOL(dependent)

\begin{tabular}{|c|c|c|c|c|c|c|c|c|c|c|c|c|c|c|c|c|}
\hline \multirow{4}{*}{ Women'sCharacteristics } & \multicolumn{8}{|c|}{ Breast } & \multicolumn{8}{|c|}{ Gynecological } \\
\hline & \multicolumn{4}{|c|}{ Study } & \multicolumn{4}{|c|}{ Control } & \multicolumn{4}{|l|}{ Study } & \multicolumn{4}{|c|}{ Control } \\
\hline & \multicolumn{2}{|c|}{ Pre } & \multicolumn{2}{|c|}{ Post } & \multicolumn{2}{|c|}{ Pre } & \multicolumn{2}{|c|}{ Post } & \multicolumn{2}{|c|}{ Pre } & \multicolumn{2}{|c|}{ Post } & \multicolumn{2}{|c|}{ Pre } & \multicolumn{2}{|c|}{ Post } \\
\hline & Beta & $\begin{array}{c}\text { P. } \\
\text { value }\end{array}$ & Beta & $\begin{array}{c}\text { P. } \\
\text { value }\end{array}$ & Beta & \begin{tabular}{|c|}
$\mathbf{P .}$ \\
value
\end{tabular} & Beta & \begin{tabular}{|c|}
$P$. \\
value
\end{tabular} & Beta & \begin{tabular}{|c|} 
P. \\
value
\end{tabular} & Beta & $\begin{array}{c}\text { P. } \\
\text { value }\end{array}$ & Beta & $\begin{array}{c}\text { P. } \\
\text { value }\end{array}$ & Beta & $\begin{array}{c}\text { P. } \\
\text { value }\end{array}$ \\
\hline \multicolumn{17}{|l|}{ Female Sexual Function } \\
\hline \multicolumn{17}{|l|}{$\begin{array}{l}\text { Complains after first dose and throughout the } \\
\text { treatment }\end{array}$} \\
\hline psychosomatic symptoms & -0.150 & 0.441 & -0.465 & $0.035^{*}$ & - & - & - & - & 0.214 & 0.643 & 0.021 & 0.960 & - & - & - & - \\
\hline $\begin{array}{l}\text { continuous pain in leg, weakness, loss of balance, } \\
\text { headache, hair loss }\end{array}$ & - & - & - & - & - & - & - & - & - & - & 0.000 & 1.000 & 0.083 & 0.863 & 0.117 & 0.806 \\
\hline $\begin{array}{l}\text { Vomiting, nausea, knee pain, dyspnea, cough, bad } \\
\text { psychological status }\end{array}$ & -0.241 & 0.170 & -0.004 & 0.982 & 0.097 & 0.660 & 0.198 & 0.406 & 0.002 & 0.994 & -0.370 & 0.272 & - & - & - & - \\
\hline $\begin{array}{l}\text { Nausea, dizziness, fatigue, headache, pain, hair } \\
\text { loss, fever, diarrhea, loss of appetite }\end{array}$ & - & - & - & - & 0.120 & 0.681 & 0.078 & 0.802 & - & - & - & - & - & - & - & - \\
\hline Colicky pain, constipation, headache, knee pain & - & - & - & - & -0.212 & 0.345 & 0.206 & 0.387 & - & - & - & - & - & - & - & - \\
\hline \multicolumn{17}{|l|}{ Complain after completion of doses } \\
\hline Vomiting & - & - & - & - & -0.178 & 0.323 & -0.210 & 0.277 & - & - & - & - & - & - & - & - \\
\hline Breast mass & - & - & - & - & 0.008 & 0.972 & -0.201 & 0.398 & - & - & - & - & - & - & - & - \\
\hline psychosomatic symptoms & - & - & - & - & - & - & - & - & - & - & - & - & 0.586 & 0.236 & -0.522 & 0.421 \\
\hline $\begin{array}{l}\text { Continuous pain in leg, weakness, loss of balance, } \\
\text { headache, hair loss }\end{array}$ & - & - & - & - & 0.104 & 0.562 & 0.080 & 0.672 & - & - & -0.328 & 0.470 & - & - & - & - \\
\hline Headache, leg pain & - & - & - & - & -0.144 & 0.446 & -0.181 & 0.372 & -0.558 & 0.274 & - & - & 0.053 & 0.902 & -1.252 & 0.157 \\
\hline $\begin{array}{l}\text { Vomiting, nausea, knee pain, dyspnea, cough, bad } \\
\text { psychological status }\end{array}$ & 0.015 & 0.930 & $\begin{array}{c}- \\
0.201 \\
\end{array}$ & 0.285 & 0.067 & 0.721 & 0.020 & 0.922 & - & - & -0.420 & 0.285 & - & - & - & - \\
\hline Pain in the body & 0.352 & 0.062 & 0.212 & 0.284 & 0.203 & 0.264 & 0.182 & 0.343 & $\begin{array}{c}- \\
0.169 \\
\end{array}$ & 0.669 & -0.399 & 0.241 & -0.347 & 0.348 & -0.391 & 0.295 \\
\hline No complain & -0.097 & 0.645 & 0.026 & 0.910 & 0.475 & $0.033^{*}$ & 0.460 & $0.049 *$ & $\begin{array}{c}- \\
0.210 \\
\end{array}$ & 0.536 & -0.031 & 0.926 & 0.700 & 0.176 & -0.361 & 0.565 \\
\hline $\begin{array}{l}\text { Nausea, dizziness ,fatigue, headache, pain, hair } \\
\text { loss, fever ,diarrhea, loss of appetite }\end{array}$ & -0.179 & 0.361 & 0.263 & 0.217 & - & - & - & - & \begin{tabular}{c|}
- \\
0.413 \\
\end{tabular} & 0.289 & - & - & -0.380 & 0.596 & -2.052 & 0.079 \\
\hline Deterioration & - & - & - & - & 0.186 & 0.343 & 0.043 & 0.835 & - & - & - & - & - & - & - & - \\
\hline Vomiting and Constipation & 0.090 & 0.702 & 0.042 & 0.871 & - & - & - & - & - & - & 1.085 & 0.091 & - & - & - & - \\
\hline \multicolumn{17}{|l|}{ Cancer Specific Stress } \\
\hline \multicolumn{17}{|l|}{$\begin{array}{l}\text { Complains after first dose and throughout the } \\
\text { treatment }\end{array}$} \\
\hline psychosomatic symptoms & -0.114 & 0.621 & \begin{tabular}{c|}
- \\
0.033 \\
\end{tabular} & 0.880 & - & - & - & - & 0.659 & 0.273 & 0.046 & 0.927 & - & - & - & - \\
\hline $\begin{array}{l}\text { continuous pain in leg, weakness, loss of balance, } \\
\text { headache, hair loss }\end{array}$ & - & - & - & - & - & - & - & - & - & - & 0.407 & 0.309 & $\begin{array}{c}- \\
0.165 \\
\end{array}$ & 0.795 & -0.496 & 0.501 \\
\hline $\begin{array}{l}\text { Vomiting, nausea, knee pain, dyspnea, cough, bad } \\
\text { psychological status }\end{array}$ & 0.093 & 0.648 & -0.072 & 0.711 & 0.144 & 0.532 & -0.085 & 0.704 & 0.108 & 0.789 & 0.712 & 0.111 & - & - & - & - \\
\hline $\begin{array}{l}\text { Nausea, dizziness, fatigue, headache, pain, hair } \\
\text { loss, fever, diarrhea, loss of appetite }\end{array}$ & - & - & - & - & -0.149 & 0.623 & 0.441 & 0.149 & - & - & - & - & - & - & - & - \\
\hline
\end{tabular}


Survivorship in Women Undergoing Gynecological and Breast Cancer Treatment in Upper Egypt: The Impact of Quality of Life Improvement Educational Program

\begin{tabular}{|c|c|c|c|c|c|c|c|c|c|c|c|c|c|c|c|c|}
\hline Colicky pain, constipation, headache, knee pain & - & - & - & 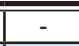 & 0.285 & 0.224 & -0.219 & 0.333 & - & - & - & - & 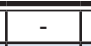 & 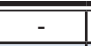 & - & - \\
\hline \multicolumn{17}{|l|}{ Complain after completion of doses } \\
\hline Vomiting & - & - & - & - & 0.125 & 0.499 & -0.098 & 0.586 & - & - & - & - & - & - & - & - \\
\hline Loss of weight & - & - & - & - & \begin{tabular}{|l|}
- \\
\end{tabular} & - & -1 & - & 0.336 & 0.424 & - & - & - & - & - & - \\
\hline Breast mass & - & - & - & - & -0.403 & 0.092 & -0.493 & $0.039 *$ & - & - & - & - & - & - & - & - \\
\hline psychosomatic symptoms & - & - & - & - & - & - & - & - & - & - & - & - & 0.285 & 0.624 & 0.554 & 0.554 \\
\hline $\begin{array}{l}\text { Continuous pain in leg, weakness, loss of balance, } \\
\text { headache, hair loss }\end{array}$ & - & - & - & - & -0.016 & 0.931 & 0.055 & 0.758 & - & - & 0.254 & 0.634 & - & - & - & - \\
\hline Headache, leg pain & - & - & - & - & -0.071 & 0.717 & 0.150 & 0.435 & \begin{tabular}{|c|}
- \\
0.060 \\
\end{tabular} & 0.916 & - & - & 0.150 & 0.793 & 0.056 & 0.959 \\
\hline \begin{tabular}{|l|} 
Vomiting, nausea, knee pain, dyspnea, cough, bad \\
psychological status
\end{tabular} & -0.095 & 0.640 & 0.053 & 0.786 & -0.027 & 0.889 & 0.188 & 0.329 & - & - & 0.394 & 0.390 & - & - & - & - \\
\hline Pain in the body & 0.182 & 0.400 & 0.050 & 0.805 & -0.005 & 0.978 & -0.127 & 0.482 & \begin{tabular}{|c|}
- \\
0.018 \\
\end{tabular} & 0.970 & 0.448 & 0.267 & \begin{tabular}{c|c}
- \\
0.182 \\
\end{tabular} & 0.689 & 0.454 & 0.396 \\
\hline No complain & 0.005 & 0.984 & 0.024 & 0.920 & -0.185 & 0.390 & -0.545 & $0.017 *$ & 0.166 & 0.682 & -0.052 & 0.897 & 0.580 & 0.348 & 0.554 & 0.554 \\
\hline $\begin{array}{l}\text { Nausea, dizziness ,fatigue, headache, pain, hair } \\
\text { loss, fever ,diarrhea, loss of appetite }\end{array}$ & 0.061 & 0.790 & $\begin{array}{c}- \\
0.207\end{array}$ & 0.349 & - & - & - & - & \begin{tabular}{c|} 
\\
0.585 \\
\end{tabular} & 0.227 & - & - & 0.580 & 0.544 & 0.742 & 0.569 \\
\hline Deterioration & - & - & - & - & 0.051 & 0.797 & 0.081 & 0.680 & - & - & - & - & - & - & - & - \\
\hline Vomiting and Constipation & 0.126 & 0.654 & 0.087 & 0.744 & - & - & - & - & - & - & 0.009 & 0.988 & - & - & - & - \\
\hline \multicolumn{17}{|l|}{ Quality of life } \\
\hline \multicolumn{17}{|c|}{\begin{tabular}{|l|l|l|l|l|}
$\begin{array}{l}\text { Complains after first dose and throughout the } \\
\text { treatment }\end{array}$ & & & \\
\end{tabular}} \\
\hline psychosomatic symptoms & 0.222 & 0.276 & 0.140 & 0.467 & - & - & - & - & 0.126 & 0.415 & \begin{tabular}{|l|}
-0.140 \\
\end{tabular} & $0.027^{*}$ & - & - & - & - \\
\hline $\begin{array}{l}\text { continuous pain in leg, weakness, loss of balance, } \\
\text { headache, hair loss }\end{array}$ & - & - & - & - & - & - & - & - & - & - & 0.407 & $0.000^{* * *}$ & \begin{tabular}{|c|}
- \\
0.163 \\
\end{tabular} & 0.771 & -0.451 & 0.103 \\
\hline $\begin{array}{l}\text { Vomiting, nausea, knee pain, dyspnea, cough, bad } \\
\text { psychological status }\end{array}$ & 0.219 & 0.228 & -0.015 & 0.929 & 0.308 & 0.252 & $|-0.130|$ & 0.573 & 0.275 & $0.053^{*}$ & -0.051 & 0.161 & - & - & - & - \\
\hline $\begin{array}{l}\text { Nausea, dizziness, fatigue, headache, pain, hair } \\
\text { loss, fever, diarrhea, loss of appetite }\end{array}$ & - & - & - & - & 0.224 & 0.521 & 0.318 & 0.305 & - & - & - & - & - & - & - & - \\
\hline Colicky pain, constipation, headache, knee pain & - & - & - & - & 0.183 & 0.490 & $\mid-0.197$ & 0.397 & - & - & - & - & - & - & - & - \\
\hline \multicolumn{17}{|l|}{ Complain after completion of doses } \\
\hline Vomiting & - & - & - & - & 0.231 & 0.284 & 0.205 & 0.279 & - & - & - & - & - & - & - & - \\
\hline Loss of weight & - & - & - & - & - & - & \begin{tabular}{|l|l|}
- & \\
\end{tabular} & - & 0.309 & $0.037^{*}$ & - & - & - & - & - & - \\
\hline Breast mass & - & - & - & - & 0.093 & 0.724 & -0.110 & 0.634 & - & - & - & - & \begin{tabular}{l|l}
- & \\
\end{tabular} & - & - & - \\
\hline \begin{tabular}{|l|} 
psychosomatic symptoms \\
\end{tabular} & - & - & - & - & - & - & \begin{tabular}{|l|l|}
- & \\
\end{tabular} & - & - & - & - & - & 0.316 & 0.541 & 0.584 & 0.101 \\
\hline $\begin{array}{l}\text { Continuous pain in leg, weakness, loss of balance, } \\
\text { headache, hair loss }\end{array}$ & - & - & - & - & -0.135 & 0.526 & 0.064 & 0.732 & - & - & 0.193 & $0.010^{* *}$ & - & - & - & - \\
\hline \begin{tabular}{|l|} 
Headache, leg pain \\
\end{tabular} & - & - & - & - & 0.180 & 0.426 & 0.422 & $0.045^{*}$ & 0.573 & $0.016^{*}$ & - & - & 0.455 & 0.395 & 0.757 & 0.084 \\
\hline $\begin{array}{l}\text { Vomiting, nausea, knee pain, dyspnea, cough, bad } \\
\text { psychological status }\end{array}$ & -0.159 & 0.378 & $\begin{array}{c}- \\
0.206 \\
\end{array}$ & 0.232 & 0.222 & 0.329 & 0.207 & 0.300 & - & - & 0.392 & $0.000 * *$ & - & - & - & - \\
\hline Pain in the body & 0.308 & 0.112 & 0.086 & 0.633 & 0.131 & 0.537 & 0.030 & 0.871 & \begin{tabular}{c|}
- \\
0.163 \\
\end{tabular} & 0.239 & 0.273 & $0.001^{* * *}$ & $\begin{array}{c}- \\
0.481 \\
\end{array}$ & 0.276 & 0.200 & 0.241 \\
\hline No complain & 0.091 & 0.678 & $\begin{array}{c}- \\
0.093 \\
\end{array}$ & 0.655 & -0.339 & 0.179 & -0.335 & 0.133 & 0.107 & 0.346 & -0.049 & 0.204 & 0.260 & 0.611 & 0.223 & 0.437 \\
\hline $\begin{array}{l}\text { Nausea, dizziness ,fatigue, headache, pain, hair } \\
\text { loss, fever ,diarrhea, loss of appetite }\end{array}$ & -0.007 & 0.972 & $\begin{array}{c}- \\
0.406 \\
\end{array}$ & 0.043 & - & - & - & - & \begin{tabular}{|c|}
- \\
0.774 \\
\end{tabular} & $0.002^{* *}$ & - & - & 1.237 & 0.196 & 1.799 & $0.014 *$ \\
\hline Deterioration & - & - & \begin{tabular}{|l|l}
- \\
\end{tabular} & - & 0.121 & 0.601 & 0.246 & 0.233 & - & - & - & - & - & - & - & - \\
\hline Vomiting and Constipation & -0.076 & 0.758 & $\begin{array}{c}- \\
0.292 \\
\end{array}$ & 0.219 & - & - & - & - & - & - & -0.336 & $0.003^{* *}$ & - & - & - & - \\
\hline
\end{tabular}

Pearson correlation coefficient $* P<0.05$ mild Statistical significant.

** $P<0.01$ moderate Statistical significance. $\quad * * * P<0.001$ highly Statistical significant.

American Research Journal of Gynaecology

Page 18 
Survivorship in Women Undergoing Gynecological and Breast Cancer Treatment in Upper Egypt: The Impact of Quality of Life Improvement Educational Program

Table8. The relationship between CSS of women with breast and gynecological cancer their and QOL at initial and last session.

\begin{tabular}{|c|c|c|c|c|c|c|c|c|c|c|c|c|c|c|c|c|}
\hline & \multicolumn{8}{|c|}{ Breast } & \multicolumn{8}{|c|}{ Gynecological } \\
\hline & \multicolumn{4}{|c|}{ Study } & \multicolumn{4}{|c|}{ Control } & \multicolumn{4}{|c|}{ Study } & \multicolumn{4}{|c|}{ Control } \\
\hline c & \multicolumn{2}{|c|}{$\begin{array}{c}\text { Impact of } \\
\text { Events } \\
\text { Scale before } \\
\text { program }\end{array}$} & \multicolumn{2}{|c|}{$\begin{array}{c}\text { Impact of Events } \\
\text { Scale after } \\
\text { program }\end{array}$} & \multicolumn{2}{|c|}{$\begin{array}{c}\text { Impact of } \\
\text { Events } \\
\text { Scale before } \\
\text { program }\end{array}$} & \multicolumn{2}{|c|}{$\begin{array}{l}\text { Impact of } \\
\text { Events } \\
\text { Scale after } \\
\text { program }\end{array}$} & \multicolumn{2}{|c|}{$\begin{array}{c}\text { Impact of Events } \\
\text { Scale before } \\
\text { program }\end{array}$} & \multicolumn{2}{|c|}{$\begin{array}{c}\text { Impact of } \\
\text { Events Scale } \\
\text { after program }\end{array}$} & \multicolumn{2}{|c|}{$\begin{array}{c}\text { Impact of } \\
\text { Events } \\
\text { Scale before } \\
\text { program }\end{array}$} & \multicolumn{2}{|c|}{$\begin{array}{c}\text { Impact of Events } \\
\text { Scale after } \\
\text { program }\end{array}$} \\
\hline QOL & $\mathbf{r}$ & p. value & $\mathbf{r}$ & p. value & $\mathbf{r}$ & p. value & $\mathbf{r}$ & p. value & $\mathbf{r}$ & p. value & $\mathbf{r}$ & p. value & $\mathbf{r}$ & p. value & $\mathbf{r}$ & p. value \\
\hline Physical well-being & 0.52 & $0.002^{* *}$ & 0.63 & $0.000^{* * *}$ & 0.37 & 0.037 & 0.67 & $0.000^{* * *}$ & 0.66 & $0.003^{* *}$ & 0.11 & 0.664 & 0.43 & 0.073 & 0.13 & 0.619 \\
\hline Emotional well-being & 0.33 & $0.061^{*}$ & 0.04 & 0.816 & 0.10 & 0.598 & 0.32 & 0.078 & -0.03 & 0.894 & 0.48 & $0.046^{*}$ & 0.14 & 0.569 & 0.35 & 0.156 \\
\hline Social well-being & 0.60 & $0.000^{* * *}$ & 0.40 & $0.024^{*}$ & 0.47 & $0.007^{* *}$ & 0.70 & $0.000^{* * *}$ & 0.52 & $0.027^{*}$ & 0.55 & $0.019^{*}$ & 0.54 & $0.022^{*}$ & 0.73 & $0.001^{* * *}$ \\
\hline Functional well-being & 0.47 & $0.006^{* * *}$ & 0.58 & $0.001^{* * *}$ & 0.25 & 0.160 & 0.38 & $0.033^{*}$ & 0.38 & 0.123 & 0.26 & 0.289 & 0.40 & 0.102 & $0.00^{* * *}$ & 0.997 \\
\hline Additional concerns & 0.35 & $0.048^{*}$ & 0.67 & $0.000^{* * *}$ & 0.20 & 0.279 & 0.42 & $0.017^{*}$ & 0.28 & 0.268 & -0.01 & 0.981 & -0.08 & 0.738 & -0.29 & 0.239 \\
\hline Total Score QOL & 0.61 & $0.000^{* * *}$ & 0.78 & $0.000^{* * *}$ & 0.40 & $0.023^{*}$ & 0.64 & $0.000^{* * *}$ & 0.58 & $0.011^{*}$ & 0.38 & 0.122 & 0.35 & 0.155 & 0.32 & 0.191 \\
\hline
\end{tabular}

Pearson correlation coefficient * $P<0.05$ mild Statistical significant.

${ }^{* *} P<0.01$ moderate Statistical significance. $\quad{ }^{* * *} P<0.001$ highly Statistical significant.

\section{DisCUSSION}

Quality Of Life (QOL) has become an increasingly attractive subject in recent decades, drawing attention from both enthusiasts and researchers. ${ }^{[7,5]}$ The therapeutic approach of patients with gynecological and breast cancer involves a high degree of concern regarding their survival. ${ }^{[34]}$ The diagnosis of cancer generally has a devastating effect on the life of the recipient. In this way, cancer is still a difficult secret to be shared, narrated and heard, even for women who are culturally more encouraged to share, integrate and socialize experiences, which probably compromises their QOL. However, while survival has increased, benefits related to QOL have not been achieved.

Quality of life comprised of broad concepts that relating global life satisfaction, including health, appropriate housing, employment, sense of security, interrelationships, education, etc. Many researchers consider QOL as the general well-being of individuals \& societies, outlining negative \& positive features of life. Researchers relate to QOL components of happiness \& satisfaction with life, For example, Aristotle, one of the first scholars which defined QOL noted: "Both the multitude \& persons of refinement conceive "the good life" or "doing well" to be the same thing as "being happy" (384-322 BC; 3). ${ }^{[33]}$ Quality of life (QOL) issues are of interest in oncology because effective modern methods of treatment and detection have led to an increase in the number of longterm survivors. So, the present study aimed to assess the effectiveness of an educational program on QOL improvement in women undergoing treatment for gynecological and breast cancer.

The National Comprehensive Cancer Network (NCCN) has consistently emphasized the need for high-quality survivor cancer care from the patient's perspective. Quality of life can be negatively impacted by survivors' negative beliefs about symptoms management and by perceived negativity from their healthcare providers. ${ }^{[35]}$ Intrusive, negative thoughts can lead to stress-related problems including emotional distress and physical functioning. ${ }^{[36]}$ Finally, satisfaction with healthcare is associated with survivors' psychological well-being and trust in their community's generosity and goodness. ${ }^{\left[{ }^{[7]}\right.}$ The negative effects from lack of transition and quality follow up information are manifested in poor QOL experiences, delays in recurrent and or ongoing treatment, patient information gaps, excessive reimbursement, and inadequate attention to psychosocial issues. ${ }^{[38]}$ 
Survivorship in Women Undergoing Gynecological and Breast Cancer Treatment in Upper Egypt: The Impact of Quality of Life Improvement Educational Program

Most of the studies have focused on the QOL in cancer patients, and the less attention has been paid to the impact of the disease on close relationships of couples in various aspects, sexual excitement, love, devotion, commitment, and satisfaction Sexual problems in women with gynecological cancer and breast cancer are decreased sexual desire, dyspareunia, vaginal dryness related to the size, and type of treatment. Previous research has estimated that sexual dysfunction occurs in about $50 \%$ of women with gynecological cancer. ${ }^{[39]}$ The most commonly reported physical sexual concern is dyspareunia. For some survivors, emotional distress related to the pain experienced with sexual intercourse may persist for several years. ${ }^{[40]}$

According to the Egyptian family culture, the marital relationship is a highly personal and private matter and it should be noted that sexual orientation is one of the least important aspects of life that isn't strongly related to women QOL. In relation to sexual function, the results of the present study declare a statistical significant difference in relation to impact of the health education program on sexual function, as there was a significant change in the mean sexual function index in the initial and last follow-up session among, as it increased from $(12 \pm 10.1)$ to $(17.6 \pm 10.6)$ \& from $(12.1 \pm 10.4)$ to $(22.1 \pm 8.1)$ in both gynecologic and breast study groups, respectively. The improvement appeared in all parameter of sexual function; desire, arousal, lubrication, orgasm, and satisfaction. Moreover, pain subscales in both study groups. This achievement in sexual function may be attributed to health education program which offers an opportunity to facilitate further contacts leading to earlier recognition of sexual problems. Moreover, assessment of a woman's sexual function prior to her cancer diagnosis can help establish which sexuality changes are due to the cancer treatment and may allow tailoring interventions accordingly. Some may prefer to avoid intercourse due to pain or anxiety, or fear of cancer spread to her husband. Thus patients can have significant benefits from discussing their concerns specializing in these issues so removing anxiety about inability to resume vaginal intercourse post-treatment. Discussing this with patients can be challenging but can often reduce anxiety following treatment.

These results are in accordance with many researchers as they stated; educational and counseling interventions, particularly those targeting sexual dysfunction, improved various aspects of sexual health. The key to the effectiveness of interventions was the attempt to identify individual strengths and to improve patients' awareness and to train them on appropriate skills, because raising awareness of the problem and its related factors leads to the use of appropriate skill to solve it. ${ }^{[41]}$ Many of the sexual problems that women struggle with, whether it is dyspareunia, menopausal symptoms, or low libido, can be made much better with time and some intervention. Lack of knowledge in healthcare providers may be a significant barrier to discussions marital relation problems. Moreover, patients may be embarrassed to raise sexual function with healthcare providers. Because of the long treatment process, there is a need to be more contacts with the patients to answer their questions and to solve their problems. In fact, this was done in the present study and through attendance in the sessions and telephone contact attempted to answer patients' questions with empathic listening and the atmosphere for supporting and providing information to enable their problem solving, their self-care and their increased abilities to cope with the problems.

Several findings were consistent in study by Anderson et al., 2015 in Australia who studied facilitating lifestyle changes to manage menopausal symptoms in women with breast cancer: a randomized controlled pilot trial of the Pink women's wellness program, who found improvements in sexual function were observed in the intervention group compared to controls, and with Jeffries et al., 2006 in Canada who studied an effective group psycho-educational intervention for improving compliance with vaginal dilation and found that, nurseled psychosexual counseling can significantly improve sexual function in patients with gynecology cancer. Also, with Powell et al., 2008 in San Francisco who investigated a randomized study of the effectiveness of a brief psychosocial intervention for women attending gynecologic cancer and found education and counseling for women after cancer treatment may also reduce sexual problems and improve marital relationship. ${ }^{[42-44]}$ 
Survivorship in Women Undergoing Gynecological and Breast Cancer Treatment in Upper Egypt: The Impact of Quality of Life Improvement Educational Program

Interestingly these findings are consistent with Brotto et al., 2008 in Columbia who developed a psycho-educational intervention for sexual dysfunction in women with gynecologic cancer and found that the psycho-educational intervention was associated with positive effect on sexual desire, arousal, orgasm, satisfaction, sexual distress, depression, and overall well-being. ${ }^{[45]}$

The results of the present study reveal no significant correlation of female sexual function with sociodemographic data on neither study group nor control group of breast cancer. There was only a significant negative correlation with age and positive correlation with age of menarche in the study group of gynecological cancer pre/post administration of the program; in the control group,there was a significant positive correlation with menopausal state. As mentioned before due to homogeneity of the groups, and the fact that marital relationship is a highly personal and private matter, and women tried to manage physical and psychological problems related to marital relation to satisfy their religious and spiritual duties and the health education program with follow up and support was effective in improving sexual function regardless their characteristics. The findings of the present study are in line with Yektatalab et al., 2015 in Croatia who studied sexual dysfunction in breast cancer survivor and indicated no significant relationship between sexual disorders and age, education level, andoccupation. ${ }^{[46]}$ Conversely, the devastating effects of premature menopause in young women was shown inthe study carried out by Ochsenkuhn et al., 2011 in Germany who studied' menopausal status inbreast cancer patients with past chemotherapy determines long-term hypoactive sexual desire disorder' and reported that sexual function was most impaired in the women with no longer menstruation after chemotherapy. ${ }^{[4]]}$

It was interesting to learn that the cancer diagnosis was indeed experienced as unexpected by the vast majority of patients with subjective judgment between the severity of the cancer-related burden already experienced and the burden expected in the future. The results of the present study showed that the vast majority of both women with gynecological or breast cancer either study $(81.3 \%$ \& $72.2 \%)$ or control $(81.3 \& 83.3 \%)$, respectively, who were undergoing cancer treatment, were had severe traumatic stress disorder (STSD) preadministration of the program. These results are in line with Hassan et al., 2016 who studied emotional distress associated with gynecologic \& breast cancer in Beni-Suef city. Their results illustrate the relationship between breast \& gynecologic cancer of the studied subjects and their emotional distress. It was noted that all types of gynecologic and breast cancer, women suffered from different degrees of anxiety and depression. In addition, breast and gynecological cancers have significant relations with symptoms of the anxiety scale score $(\mathrm{P}<0.05)$. ${ }^{[13]}$ The high percentage of STSD may be attributed to the type of treatment procedures as surgical intervention may women's sexual health as a result of direct anatomic changes (mastectomy, Hysterectomy, radical surgeries, part of the vagina may be removed) or changes in the hormonal milieu as aresult of treatment (oophorectomy). In addition, body image can be disrupted as a result of surgery, and this can affect sexual recovery. ${ }^{[48,49]}$ In younger women, chemotherapy is also a strong risk factor for amenorrhea and early menopause. Finally, women who receive radiation therapy (RT) for a genital or pelvic cancer are more liable to short-term toxicities (include incontinence of either urine or stool), irritation, and pain, all of which can dampen libido. Long-term side effects include fibrosis, which can cause vaginal stenosis or, at its most severe, agglutination of the vaginal vault, causing obliteration of the canal. ${ }^{[48]}$

In relation to CSS, there is there is no significant correlation between socio-demographic data and CSS as regards study and control groups of the studied women of both breast and gynecological cancer except on the control group of the breast cancer; there was a significant negative correlation with occupation pre-administration of the program. Also, in the study group in gynecological cancer, there was a significant negative correlation with occupation after implementation of the program. This study supports meeting both the physical and psychological burdens associated with cancer and its treatment. These findings contradict with Levin, 2013 who found that receiving hormonal therapy was associated withCSS $(r=0.38, p>0.01) .{ }^{[50]}$ Also, depression and 
Survivorship in Women Undergoing Gynecological and Breast Cancer Treatment in Upper Egypt: The Impact of Quality of Life Improvement Educational Program

anxiety are common among oncology patients and could negatively affect drug efficacy, treatment adherence, and survivorship quality of life (QOL) ${ }^{[25,13]}$ Data show that behavioral factors such as social support and distress are associated with changes in cellular immune responses. Behavioral factors are also known to be associated with angiogenic mechanisms in blood and in the tumor microenvironment. ${ }^{[1,52]}$

There is obviously clear the effect of the health education program on traumatic stress reactions to cancer diagnosis and treatment, as $81.3 \% \& 72.2 \%$ of the breast and gynecological cancer study group had severe traumatic stress disorder pre-administration of the program and decreased to ( $15.6 \% \& 22.2)$, respectively, while the healthy women with no stress in the same groups increased from $(6.3 \%$ \& 11.1) to $(40.6 \%$ \& 55.6) after administration of the program. This is may be attributed to that, patients going through breast and gynecological cancer diagnosis and treatment are almost always apprehensive, frightened, and confused. Answering questions and lowering barriers to good patient, oncologist, and healthcare providers communication can be very helpful. ${ }^{[53]}$ In order to enhance psychological adjustment to cancer and its treatment, this group of patients learned to use avoidant behavior, warding off repeated thoughts about the stressful event as having cancer and receiving treatment to decrease a stress reaction. Also teaching them to manage their physical \& mental health problems concurrently with meeting with family members and informing them about management strategies and facilitating communication between patients and medical providers were also vital components.

These findings are in line with Lohet al., 2013 in Malaysia who studied the effectiveness of a patient selfmanagement program for breast cancer as a chronic illness and stated that the differential positive impact on depression, anxiety, and stress. ${ }^{[54]}$ Also with findings from a study by Brewin et al.,1999 in London who studied memory processes and the course of anxiety \& depression in cancer patients, where the importance of IES intrusion as a predictor for prolonged adverse psychological reactions in cancer patients indicated the importance of interventions in order to facilitate psychological adjustment. ${ }^{[55]}$ Moreover with findings of Loizzo et al., 2010 in Texas who studied the effect of a contemplative self-healing program on QOL in women with breast \& gynecologic cancers and found a reduction in distress and disability among female breast and gynecological cancers survivors with contemplative self-healing program. ${ }^{[56]}$

'Quality of Life' as an individual's perception of their position in life in the context of the culture and value systems in which they live and in relation to their goals, expectations, standards, and concerns. The research results showed that QOL of the patients with breast \& gynecological cancer has been enhanced under the influence of health education program and this improvement has not been only related to the total score of the QOL but has occurred in all its dimensions. Thus, it can be said that health education program enhances physical, social, psychological, and functional dimensions of QOL of the patients with breast and gynecological cancer, and on enabling women to proactively live with a cancer condition, in a traditional setting with limited resources, typical of developing countries. The possible explanation is that chemotherapy (mainly) regimen lasts very long (for example, 24 weeks) the patient will visit the outpatient clinic every 3 to 4 weeks that is, 6 to 8 times. It is likely that the patient builds a relationship with the researcher caring for her, which might also add to improvements in QOL, and due to high interest and compliance to cancer treatment, we found that the majority of the studied women were able to complete the five sessions for the intervention. So that a long-term follow-up of the patients in the intervention group might well show an improvement in QOL compared with the patients in the control group.

These findings were concurrent with the study reported by Klafke et al., 2015 in Germany who evaluate the effectiveness of an intervention involving CAM therapies and counseling on CAM as complementing the supportive care of breast and gynecologic cancer patients undergoing chemotherapy. It is hypothesized that this intervention increases HRQOL and clustered symptoms over the chemotherapy regimen and follow-up in this outpatient population. ${ }^{[57]}$ Also with findings of Shahsavari et al., 2015 who studied the effect of self-care 
Survivorship in Women Undergoing Gynecological and Breast Cancer Treatment in Upper Egypt: The Impact of Quality of Life Improvement Educational Program

education on the QOL in patients with breast cancer and showed that QOL of the patients with breast cancer has been enhanced under the influence of self-care education. ${ }^{[58]}$ Moreover, with Loh et al., 2013 who stated that all dimensions of QOL increased significantly in the intervention group after performing a one-month selfmanagement program compared with the control one. ${ }^{\left[{ }^{44]}\right.}$ Additionally, these findings aren't in line with Speck et al., 2010 in Philadelphia USA who studied changes in the body image and relationship scale following a one-year strength training trial for breast cancer survivors with or at risk for lymphedema, and found an improvement in body image perception after rehabilitative intervention (twice a week for 13 weeks), but they did not find any improvement in QOL. ${ }^{[59]}$

Interestingly, within line with Faller et al., 2011 who studied effects of psycho-oncologic interventions on emotional distress and QOL in adult patients with cancer: systematic review and meta-analysis and implied that significant small post-treatment effects were found for emotional distress, anxiety, depression, and QOL. ${ }^{[60]}$ Loizzo et al., 2010 confirmed that Participants had significant with inpatient change on FACT-G, improving by a mean of 6.2 points. ${ }^{[5]}$ In addition, they reported clinically important improvement in emotional and functional domains and social, role-emotional, and mental health status domains on SF-36, and reducing in distress and disability among female breast and gynecological cancers survivors.

Regarding the relationship between the studied women QOL and socio-demographic data in both breast and gynecological cancer, there is no significant except on the control group of gynecological cancer; there was asignificant negative correlation with rural residences after implementation of the program. These findings are contradicted Wilailak et al., 2011 in Thailand regarding association with financial status who studied QOL in gynecologic cancer survivors compared to healthy check-up women and found the QOL scores were higher in gynecologic cancer patients after treatment. The factors that associated with the higher score in the patient group are having husband as a care giver, no financial problem, Eastern Cooperative Oncology Group score 0 or 1 and having high school or higher education. ${ }^{[61]}$ Studies that examined age-related differences in women with cancer showed, compared to younger women, older women reported worse physical well-being and functioning. ${ }^{[62]}$

Moreover, it contradicts with Awadalla et al., 2007 in Kuwait who studied factors associated with QOL of out patients with breast cancer and gynecologic cancers and their family caregivers: a controlled study and found that education was the only care giver characteristic that had a significant association with patient's QOL. ${ }^{63]}$ Loizzo et al., 2010 confirmed that patients who were married, with higher education, better employment, and with longer duration of illness had higher QOL. ${ }^{[5]}$ Patients on radiotherapy and their care givers had higher QOL scores. Also, Greimel et al., 2002 in Austria who studied prospective assessment of QOL of female cancer patients, and reported that the site of disease had a marginal impact on QOL during active treatment and no impact after completion of treatment. ${ }^{[64]}$ While Chan et al., 2001 in Hong Kong, who study QOL after gynecologic cancer treatment found that age was one of the factors identified as having asignificant effect on long-term QOL after treatment. They found that younger patients had poorer QOL which might have resulted from unexpectedness of impaired fertility and femininity, treatment-related menopause and relationship issues. ${ }^{[65]}$

Regarding relationship of predictor and outcomes, there was significant correlations post- administration of the program in breast cancer group in both study and control groups, except in emotional well-being ( $\mathrm{p}>$ 0.05). Regarding the gynecological group, there was a significant positive correlation between social well-being, emotional well-being, and the entire QOL in the study group, and a significant positive correlation between social well-being, emotional well-being, and the entire QOL in the study group $(\mathrm{p}<0.05)$ after implementation the program. This may be attributed to shifting from inpatient to outpatient cancer treatment which has increased awareness of patients' self-care strategies and also of their significant others including family members and close friends. ${ }^{[57]}$ Cancer has become a family disease affecting not only the individual with the cancer diagnosis 
Survivorship in Women Undergoing Gynecological and Breast Cancer Treatment in Upper Egypt: The Impact of Quality of Life Improvement Educational Program

but also involving their significant others who often are experiencing high levels of distress while accompanying and supporting their loved one going through the treatment stages and adjusting to a new life situation. A strength of the current study is the consideration of patients' significant others, who will be interviewed during the process evaluation to gain a better understanding of the complex nursing care intervention. The interventions have been primarily composed for the patient receiving chemotherapy, and significant others who can administer the interventions. Thus, the current study will contribute to bonding and improvements of QOL in cancer patients' significant others. To our knowledge, this is one of the first nurse-led intervention studies in Egypt that can assess nurses' relevant contribution in promoting QOL during cancer therapy.

\section{CONCLUSION}

The health education program showed evidence of improved quality of life with a reduction in the sexual dysfunction, and lower stress levels. All of the study group cases who had poor quality of life had severe stress in the initial visit, while in the last visit almost of women who had good quality of life had mild stress. The findings from the present study add to the growing body of evidence that nurse-administered educational interventions are effective in helping patients manage physical and psychological symptom related to cancer treatment that negatively affect women quality of life.

\section{RECOMMENDATIONS}

Based upon findings of the current study, the following recommendations are suggested:

1. Add voice to support the educational interventions for breast and gynecological cancer by highlight the importance of nurse's roles as a health educator and add cancer-related quality of life health education to the routine cares provided to these patients by nurses as it can influence and reduces distress during treatment.

2. More robust studies are needed to investigate the longer-term effect of such programs and plan individualized education program in formulating their own education program, focusing and emphasizing on unique needs of each patient, and to facilitate the day-to-day management of people lives indefinitely with breast cancer, and especially in resource-limited developing countries.

3. This study calls for a greater study, focusing towards a better model of care for an increasing public health burden, as the numbers of breast and gynecologic cancer survivors increases worldwide. It is perhaps time for the patients to speak out, to decide for themselves on their management, to enable them to live effectively with cancer.

\section{REFERENCES}

1. Hassan H., Atwa A. Occupational Stress, Job Satisfaction and Cervical Screening Intention of Maternity Oncology Nurses, Medical Science \& Healthcare Practice, 2017; 1(1): 48-59. doi:10.22158/mshp.v1n1p48.

2. Khaled I., Mikhail N., Baraka H., Kamel H. Cancer Incidence in Egypt: Results of the National Population-Based Cancer Registry Program. Journal of Cancer Epidemiology, 2014; Article ID 437971, 18 pages

3. U.S. Department of Health and Human Services Centers for Disease Control and Prevention CDC Publication \#99-9125, August 2013. www.cdc.gov/ cancer/ knowledge 1-800-CDC-INFO.

4. Qalawa Sh., Eldeeb A., Hassan H. Young Adult Women's intention regarding breast and cervical cancer screening in Beni-Suef. Scientific Research Journal, 2015; 3(3): 11-24.

5. Emem E., Hassan H. Correlation between Quality Of Life and Dysmenorrhea among Nursing Schools Students. International Journal of Nursing Science, 2017; 7(6): 123-132. DOI: 10.5923/j.nursing.20170706.02 
Survivorship in Women Undergoing Gynecological and Breast Cancer Treatment in Upper Egypt: The Impact of Quality of Life Improvement Educational Program

6. Keng K., Hooi S. Assessing quality of life in Singapore: An exploratory study. Social Indicators Research, 1995; 35: 71-91.

7. Fayers P., Machin D. Quality of life: the assessment, analysis and interpretation of patient-reported outcomes. John Wiley \& Sons.| 2013.

8. WHO. Development of the World Health Organization WHOQOL-BREF quality of life assessment. Psychological medicine. 1998; 28(3):551-8.

9. Weaver KE., Forsythe LP., Reeve BB. Mental and physical health-related quality of life among U.S. cancer survivors: population estimates Cancer. Epidemiol Bio-markers, 2012; 21: 2108-2117.

10. Agarwal K., Agarwal A. A study of dysmenorrhea during menstruation in adolescent girls. Indian J Community Med, 2010; 35(1):159-64.

11. Centers for Disease Control and Prevention's (CDC). Inside Knowledge: Get the Facts about Gynecologic Cancer campaign. CDC Publication \#22-0098, Revised April 2017.

12. U.S. Department of Health and Human Services Centers for Disease Control and Prevention. Get the Facts About Gynecologic Cancer. 2012; CDC Publication \#22-0098, www.cdc.gov/cancer/ knowledge. 1-800-CDC-INFO.

13. Hassan, H., Bayoumi, M., Atwa, A. Emotional Distress Associated with Gynecologic and Breast Cancer in Beni-Suef City. International Journal of Science and Research, 2016; 5(2): 1118-1129.

14. Aziz M. Cancer survivorship research: State of Knowledge, challenges and opportunities. Acta Oncologica, 2007; 46: 417-432.

15. Ashing-Giwa T., Lim J., Tang J. Surviving cervical cancer: Does health-related quality of life influence survival? Gynecologic Oncology, 2010; 118: 35-42.

16. Ferrans C. Differences in what quality of life instruments measure. Natl Cancer InstMonogr, 2007; 37: 22-26.

17. Kent EE., Ambs A., Mitchell SA., Clauser SB., Smith AW., Hays RD. Health-related quality of life in older adult survivors of selected cancers:data from the SEER-MHOS linkage. Cancer, 2015; 121: 758-765.

18. Miaskowski C., Dodd M., West C., Schumacher K., Paul S., Tripathy D. Randomized clinical trial of the effectiveness of a self-care intervention to improve cancer pain management. Journal of Clinical Oncology, 2004; $22: 1713-1720$.

19. Gift A., Stommel M., Jablonski A., Given C. A cluster of symptoms over time inpatients with lung cancer. Nursing Research, 2003; 52: 393-400.

20. Timperi AV., ErgasIJ.,Rehkopf DH., Roh JM., Kwan ML., Kushi LH. Employment status and quality of life in recently diagnosed breast cancer survivors. Psych oncology, 2013; 22:1411-20.

21. Rodrigues AM. Determinants of Overall Quality Of Life in People with Advanced Cancer. Dissertation, Mcgill University of Canada, 2012.

22. CANO/ACIO. Canadian Association of Oncology Nursing Association. 2015, canadienne des infirmieres enncology. http://www.cano acio.org CC0-Cancer Care Ontario. https://www.cancercare.

23. Harhra NA., Basaleem HO. Trends of breast cancer and its management in the last twenty years in Aden and adjacent governorates, Yemen. Asian Pac J Cancer Prev, 2012; 4347-51. 
Survivorship in Women Undergoing Gynecological and Breast Cancer Treatment in Upper Egypt: The Impact of Quality of Life Improvement Educational Program

24. Green E., Johnston M., Mc Cartney G., Milliken D., Poirier S., Reynolds P. Safe Handling of Parametrial Cytotoxics. A Quality Initiative of the Program in Evidence-based Care (PEBC), Cancer Care Ontario (CCO), 2012.

25. Salander P., Lilliehorn S., Hamberg K., Kero A. The impact of breast canceron living an everyday life 4.5-5 years post-diagnosis - a qualitative prospectivestudy of 39. ActaOncologica, 2011; 0284-186.

26. Hewitt M., Greenfield S., Stovall E. Cancer patient to cancer survivor: Lost in transition. National Academies Press. 2005.

27. American cancer society: Cancer during pregnancy, 2015b. available at www.cancer.org

28. Bhalwar R. Text book of Public Health and Community Medicine 1st ed. Pune: Department of Community Medicine Armed Forces Medical College, 2009: 251.

29. Rosen R., Brown C., Heiman, J., Leiblum S., Meston C., Shabsigh R., D’Agostino R. The Female Sexual Function Index (FSFI): a multidimensional self-report instrument for the assessment of female sexual function. Journal of Sexualand Marital Therapy, 2000; 26(2): 191-208.

30. Wiegel M., Meston C., Rosen R. The female sexual function index (FSFI): cross-validation and development of clinical cutoff scores. J Sex Marital Therapy, 2005; 31: 1-20.

31. Weiss D. The Impact of Event Scale-Revised. In J.P. Wilson, \& T.M. Keane (Eds.) Assessing psychological trauma and PTSD: a practitioner's handbook. 2007, 2nd ed. New York: Guilford Press. 168-189

32. Christianson S., Marren J. The Impact of Event Scale - Revised (IES-R). Try this: general assessment series, Best Practices in Nursing Care to Older Adults; A series provided by The Hartford Institute for Geriatric Nursing, New York University, College of Nursing, , 2013; 19: 1-2.

33. Cella F. Functional Assessment of Chronic Illness Therapy (FACIT) measurement system manual version 4. Center on Outcomes, Research and Education (CORE). Evanston Northwestern Healthcare and North western University: IL, 1997.

34. Regino P., Elias T., Silveira C., PereiraG., Pissetti C., Silva S. Quality of Life of Patients with Breast and Gynecological CancerFaced with Anticancer Chemotherapy. International Archives of Medicine, 2017; 10(233). doi: 10.3823/2503

35. Yeom HE., Heidrich SM. Effect of perceived barriers to symptom management on quality of life in older breast cancer survivors. Cancer Nurs., 2009; 32: 309-316.

36. Lebel S., Rosberger Z., Edgar L., Devins GM. Predicting stress-related problems in long-term breast cancer survivors. J Psychosom Res, 2008; 65: 513-523.

37. Kaiser K. The meaning of the survivor identity for women with breast cancer. SocSci Med, 2008; 67: 7987.

38. Peters-Engl C., Cassik P., Schmidt I., Denison U., Medl M., Pokieser W., Sevelda P. Impact of haemoglobin levels during adjuvant chemotherapy on the survival of patients with primary breast cancer. Acta Oncologica, 2005; 44 (2): 129-133

39. Audette C., Waterman J. The sexual health of women after gynecological malignancy. Journal of Midwifery and Women's Health, 2010; 55: 357-362.

40. Reis N., Beji K., Coskun A. Quality of life and sexual functioning in gynecological cancer patients: results from quantitative and qualitative data. European Journal of Oncology Nursing, 2010; 14: 137-146.

American Research Journal of Gynaecology

Page 26 
Survivorship in Women Undergoing Gynecological and Breast Cancer Treatment in Upper Egypt: The Impact of Quality of Life Improvement Educational Program

41. Ganz PA., Kwan L., Stanton AL., Bower JE., Belin TR. Physical and psychosocial recovery in the year after primary treatment of breast cancer. J Clin Oncol, 2011; 29: 1101-1109.

42. Anderson DJ., Seib C., Mccarthy AL., Yates P., Porter-Steele J., Mcguire A. Facilitating lifestyle changes to manage menopausal symptoms in women with breast cancer: a randomized controlled pilot trial of The Pink Women's Wellness Program. Menopause. 2015.

43. Jeffries SA., Robinson JW., Craighead PS., Keats MR. An effective group psycho-educational intervention for improving compliance with vaginal dilation: A randomized controlled trial. Int J Radiat Oncol Biol Phys, 2006; 65: 404-11.

44. Powell CB., Kneier A., Chen LM., Rubin M., Kronewetter C., Levine A. Randomized study of the effectiveness of a brief psychosocial intervention for women attending a gynecologic cancer clinic. Gynecol Oncol, 2008; 111: 137-43.

45. Brotto LA., Heiman JR., Goff B., Greer B., Lentz GM., Swisher E., et al. A psycho-educational intervention for sexual dysfunction in women with gynecologic cancer. Arch Sex Behav, 2008; 37: 317-29.

46. Yektatalab S., Taleii A., Moosavinasab M., Soleimani S. Sexual Dysfunction in Breast Cancer Survivors, 2015. Available at www.SID.ir

47. Ochsenkühn R., Hermelink K., Clayton AH., et al. Menopausal status in breast cancer patients with past chemotherapy determines long-term hypoactive sexual desire disorder. J Sex Med., 2011; 8(5):1486-94.

48. Dizon D., Suzin D.,McIlvenna S. Sexual Health as a Survivorship Issue for Female Cancer Survivors. Journal List Oncologist, 2014; 19(2).

49. Becker M., Malafy T., Bossart M. Quality of life and sexual functioning in endometrial cancer survivors. Gynecol Oncol, 2011; 121: 169-173.

50. Levin 0. The Impact of Reduced Ovarian Function and Its Consequences on Young Women Survivors of Breast and Gynecologic Cancer, 2013.

51. Meraner V., Gamper EM, Grahmann A. Monitoring physical and psychosocial symptom trajectories in ovarian cancer patients receiving chemotherapy. BMC Cancer, 2012; 12: 77.

52. Yarbro CH., Wujcik D., Gobel BH. Cancer Nursing: Principles and Practice, 7th ed. Jones and Bartlett Publishers, Sudbury, MA, USA, 2011.

53. Alexander APRN, FAANP, FAAN, Versie Johnson-Mallard, ARNP, FAANP, Elizabeth Kostas-Polston. Women's Health Care in Advanced Practice Nursing, 2nd, 2016.

54. Loh SY., Packer T., Chinna K., Quek KF. Effectiveness of a patient self-management programme for breast cancer as a chronic illness: a non-randomised controlled clinical trial. J Cancer Surviv, 2013; 7(3): 331-42. Doi: 10.1007/s11764-013-0274-x.

55. Brewin C., Watson M., mccarthy S., Hyman P., Dayson D. Memory processes and the course of anxiety and depression in cancer patients. Psychol Med, 1998; 28: 219-24.

56. Loizzo J., Peterson C., Charlson E., Wolf J., Margaret A. The effect of a contemplative self-healing program on quality of life in women with breast and gynecologic cancers alternative therapies in health and medicine. Aliso Viejo, 2010;-16(3) : 30-7.

57. Klafke N., Mahler C., von Hagens C., Rochon J., Schneeweiss A., Andreas Müller A., Salize H.Joos S. A complex nursing intervention of complementary and alternative medicine (CAM) to increase quality of life in patients with breast and gynecologic cancer undergoing chemotherapy: study protocol for a partially randomized patient preference trial, 2015.

American Research Journal of Gynaecology

Page 27 
Survivorship in Women Undergoing Gynecological and Breast Cancer Treatment in Upper Egypt: The Impact of Quality of Life Improvement Educational Program

58. Shahsavari H., Matory P., Zare Z, Taleghani F., Kaji M. Effect of self-care education on the quality of life in patients with breast cancer. Educ Health Promot, 2015; 4(70). doi: 10.4103/2277-9531.171782

59. Speck R. Gross M. Hormes. Changes in the body image and relationship scale following a one-year strength training trial for breast cancer survivors with or at risk for lymphedema," Breast Cancer Research and Treatment, 2010; 121(2): 421-430.

60. Faller H., Schuler M., Richard M., Heckl U., Weis J., Küffner R. Effects of psycho-oncologic interventions on emotional distress and quality of life in adult patients with cancer: systematic review and meta-analysis. J Clin Oncol, 2013; 31(6):782-93.

61. Wilailak S., Lertkhachonsuk A., Lohacharoenvanich N., Luengsukcharoen S., Jirajaras M., Likitanasombat P., Sirilerttrakul S. Quality of life in gynecologic cancer survivors compared to healthy check-up women J Gynecol Oncol, 2011; 30; 22(2): 103-109.

62. Loerzel W., Dow H., McNees P. Why women with breast cancer use or don't use lymphedema prevention and management strategies. Conference Proceedings, American Psychosocial Oncology Society, 3rd edition, 2006.

63. Awadalla AW., Ohaeri JU., Gholoum A., Khalid AO., Hamad HM., Jacob A. Factors associated with quality of life of outpatients with breast cancer and gynecologic cancers and their family caregivers: a controlled study. BMC Cancer, 2007; 7: 102.

64. Greimel E., Thiel I., Peintinger F., Cegnar I., Pongratz E. Prospective assessment of quality of life of female cancer patients. Gynecol Oncol, 2002; 85: 140-147.

65. Chan YM., Ngan HY., Li BY., Yip AM., Ng TY., Lee PW., Yip PS., Wong LC. A longitudinal study on quality of life after gynecologic cancer treatment. Gynecol Oncol, 2001; 83(1):10-9.

Citation: Fatma Saber Nady Mohammed, Mamdouh El-Sherbiny Ramadan Shahin, Entisar Mohammed Youness, Hanan Elzeblawy Hassan, "Survivorship in Women Undergoing Gynecological and Breast Cancer Treatment in Upper Egypt: The Impact of Quality of Life Improvement Educational Program". American Research Journal of Gynaecology. 2018; 2(1): 1-28.

Copyright (c) 2018 Fatma Saber Nady Mohammed, Mamdouh El-Sherbiny Ramadan Shahin, Entisar Mohammed Youness, Hanan Elzeblawy Hassan, This is an open access article distributed under the Creative Commons Attribution License, which permits unrestricted use, distribution, and reproduction in any medium, provided the original work is properly cited. 